\title{
Inhalation of Bacterial Cellulose Nanofibrils Triggers an Inflammatory Response and Changes Lung Tissue Morphology of Mice
}

\author{
Ricardo Silva-Carvalho ${ }^{1}$, João P. Silva ${ }^{2}$, Pedro Ferreirinhaa,4, Alexandre F. Leitão ${ }^{1}$, Fábia K. \\ Andrade $^{5}$, Rui M. Gil da Costa ${ }^{6,7,8}$, Cecília Cristelo ${ }^{1}$, Morsyleide F. Rosa ${ }^{5}$, Manuel Vilanova ${ }^{3,4}$ \\ and F. Miguel Gama' \\ ${ }^{1} C E B$ - Centre of Biological Engineering, University of Minho, Braga, Portugal \\ ${ }^{2}$ UCIBIO, REQUIMTE - Laboratory of Toxicology, Department of Biological Sciences, Faculty of Pharmacy, University \\ of Porto, Porto, Portugal \\ ${ }^{3}$ ICBAS - Biomedical Sciences Institute Abel Salazar, University of Porto, Porto, Portugal \\ ${ }^{4}$ i3S - Institute for Research and Innovation in Health, University of Porto and IBMC - Institute for Molecular and Cell \\ Biology, University of Porto, Porto, Portugal \\ ${ }^{5}$ Embrapa Tropical Agroindustry, Fortaleza, Ceará, Brasil \\ ${ }^{6}$ LEPAE - Laboratory for Process, Environmental and Energy Engineering, Chemical Engineering Department, Faculty \\ of Engineering, University of Porto, Porto, Portugal \\ ${ }^{7}$ Molecular Oncology and Viral Pathology Group, CI-IPOP, Portuguese Institute of Oncology, Porto, Portugal \\ ${ }^{8}$ CITAB - Centre for the Research and Technology of Agro-Environmental and Biological Sciences, University of Trás- \\ os-Montes and Alto Douro, Vila Real, Portugal
}

\begin{abstract}
In view of the growing industrial use of Bacterial cellulose (BC), and taking into account that it might become airborne and be inhaled after industrial processing, assessing its potential pulmonary toxic effects assumes high relevance. In this work, the murine model was used to assess the effects of exposure to respirable BC nanofibrils $(\mathrm{nBC})$, obtained by disintegration of $\mathrm{BC}$ produced by Komagataeibacter hansenii. Murine bone marrow-derived macrophages (BMMФ) were treated with different doses of $\mathrm{nBC}(0.02$ and $0.2 \mathrm{mg} / \mathrm{mL}$, respectively 1 and $10 \mu \mathrm{g}$ of fibrils) in absence or presence of $0.2 \%$ Carboxymethyl Cellulose (nBCMC). Furthermore, mice were instilled intratracheally with $\mathrm{nBC}$ or $\mathrm{nBCMC}$ at different concentrations and at different time-points and analyzed up to 6 months after treatments. Microcrystaline Avicel-plus ${ }^{\circledR}$ CM 2159, a plant-derived cellulose, was used for comparison. Markers of cellular damage (lactate dehydrogenase release and total protein) and oxidative stress (hydrogen peroxidase, reduced glutathione, lipid peroxidation and glutathione peroxidase activity) as well presence of
\end{abstract}

\section{Correspondence to: Ricardo Silva-Carvalho, Department of Bio- logical Engineering, University of Minho, Campus de Gualtar, 4710-057 Braga, Portugal \\ E-mail: remanuelcarvalho@gmail.com}

This is an Open-Access article distributed under the terms of the Creative Commons Attribution Non-Commercial License (http:// creativecommons.org/licenses/by-nc/3.0) which permits unrestricted non-commercial use, distribution, and reproduction in any medium, provided the original work is properly cited.

Abbreviations: 4-HNE, 4-hydroxynonenal; BAL, Brochoalveolar lavage; $\mathrm{BC}$, Bacterial cellulose; $\mathrm{BMM} \Phi$, Bone marrow-derived macrophages; Cl, Crystallinity index; CMC, Carboxymethyl cellulose; CNCs, Cellulose nanocrystals; DLS, Dynamic Light Scattering; DTNB, 5,5'-dithio-bis-(2-nitrobenzoic acid); FBS, Fetal bovine serum; FDA, Food and Drug Administration; GPx, Glutathione Peroxidase; GSH, Glutathione; HS, Hestrin-Schramm; i.p., intraperitoneal; LAL, Limulus Amebocyte Lysate; LCCM, L929-cell conditioned medium; LDH, Lactate dehydrogenase; MDA, Malondialdehyde; MPO, Myeloperoxidase; MTT, 3-(4,5-dimethylthiazol-2yl)-2,5-diphenyltetrazolium bromide; $\mathrm{nBC}$, Bacterial cellulose nanofibrils; $n B C M C$, Bacterial cellulose nanofibrils containing carboxymethyl cellulose; OSHA, Occupational Safety \& Health Administration; PBS, Phosphate-buffered saline; PMA, Phorbol myristate acetate; $p N A, p$-Nitroaniline; RPMI, Roswell Park Memorial Institute; SDS, Sodium dodecyl sulfate; SEM, Scanning Electron Microscope; TBA, Thiobarbituric acid; TBARS, Thiobarbituric acid reactive substances; TEM, Transmission Electron Microscopy; TMB, 3,3'5,5'-tetramethyl-benzidine; TNB, 5-thio-2-nitrobenzoic acid; XRD, X-ray diffraction. 
inflammatory cells were evaluated in brochoalveolar lavage (BAL) fluids. Histological analysis of lungs, heart and liver tissues was also performed. BAL analysis showed that exposure to $\mathrm{nBCMC}$ or CMC did not induce major alterations in the assessed markers of cell damage, oxidative stress or inflammatory cell numbers in BAL fluid over time, even following cumulative treatments. Avicel-plus ${ }^{\circledR}$ CM 2159 significantly increased LDH release, detected 3 months after 4 weekly administrations. However, histological results revealed a chronic inflammatory response and tissue alterations, being hypertrophy of pulmonary arteries (observed 3 months after nBCMC treatment) of particular concern. These histological alterations remained after 6 months in animals treated with nBC, possibly due to foreign body reaction and the organism's inability to remove the fibers. Overall, despite being a safe and biocompatible biomaterial, BC-derived nanofibrils inhalation may lead to lung pathology and pose significant health risks.

Key words: Bacterial cellulose, Airborne nanofibers, Lung toxicity, Inflammation

\section{INTRODUCTION}

Cellulose-based materials have been extensively used by humans over the centuries (1). In fact, cellulose is the most abundant renewable and naturally occurring biopolymer on earth (2). It is best known as the main constituent of plant cell walls and is commonly extracted from vegetal resources $(2,3)$. Nevertheless, this biomaterial can also be produced by some bacteria as an extracellular polymer (4). The main differences between these two types of cellulose - bacterial vs plant - are that bacterial cellulose (BC) is obtained in a pure state (free of lignin, pectin or hemicellulose) and is made up of ribbons with nanometric size, which determines its very high surface area and ability to absorb large amounts of water (5). Moreover, BC is produced through a relatively simple fermentation process, while plant cellulose is isolated using hazardous chemicals (2).

Plant cellulose fibers have found their way into many products, such as widely used paper and textiles (6). BC, on the other hand, has been studied for various biomedical applications including wound dressings (7), artificial skin (8), blood vessels (9-11) and as a scaffold for tissue engineering $(4,12,13)$, due to its morphology, high purity, water-holding capacity, tensile strength, malleability $(4,5$, 14) and biocompatibility. Mostly, these applications have focused on $\mathrm{BC}$ as a stand-alone polymer, exploiting the use of the naturally occurring $\mathrm{BC}$ membranes with minimal manipulation of structural features. However, several studies have also looked at the potential of BC nanofibrils as additives to increase the mechanical strength and structural integrity of other polymeric networks, forming novel and improved composite and nanocomposite materials (3,15-18). Despite being the most available natural polymer on earth, only recently cellulose has gained prominence as a nanostructured material, in the form of nanocrystals and nano/microfibrillar cellulose (19). Various methods for the production of nanocrystals (or "nanowhiskers") and nano/microfibrillar BC have been described, such as acid hydrolysis (using sulphuric and hydrochloric acids), enzymatic hydrolysis and mechanical disintegration (20-
23). Specifically, the mechanical processes used for nanofibrillar cellulose manufacturing include shearing, grinding and/or high-pressure homogenization of pulp (24). The end-product of all these chemical and mechanical processes usually consists of needle-like nanoparticles, which assemble as a fine powder that can easily become airborne and be inhaled $(19,20,25)$.

Production of nanocellulose from plant sources has until now been performed on the laboratory scale, in up to kilogram sized batches. However, a number of manufacturing facilities around the world are now scaling up the production, aiming to produce multiple tons per day. Among these are CelluForce, Inventia, BioVision Technology, Borregaard ChemCell, Melodia, Daicel Corporation, Seiko PMC Corporation, along with several companies in Asia (26). The production of cellulose nanocrystals (CNCs) is considered environmentally safe, being the first nanomaterial that was considered as "non-toxic" and accepted on the Canada's Domestic Substance list (27). In fact, Kovacs et al. (28) performed an ecotoxicological characterization of CNCs in different aquatic species and showed that this material has low toxicological potential and environmental risk at this level.

Cellulose has been described as having a low intrinsic cellular toxicity in vitro, regardless of its origin $(21,29$, $30)$. However, the biological effects of inhaled plant cellulose fibers have already been studied and have been shown to cause cell damage and elevate the risk of developing granulomas and fibrosis (1,31-34). The pulmonary effects of inhaled BC nanofibrils, a more pristine biomaterial (compared to plant cellulose), remains undetermined. With the emergence of nanocellulose as a new industrial product and considering the plethora of potential applications for $\mathrm{BC}$ nano- and micro-whiskers, the assessment of the toxicological effects and risks of airborne BC nanofibers assumes particular relevance.

In this work, we investigated putative harmful effects of BC nanofibrils in mouse lungs. BC nanofibrils were administered intratracheally to mice and several toxicityassociated parameters were evaluated in the lungs and bronchoalveolar lavage fluids (BAL) collected at different 
time-points, up to 6 months. To our knowledge, this work represents the first toxicological assessment of inhaled BC nanofibrils, thus assuming particular relevance to the industry of $\mathrm{BC}$ manufacturing and processing.

\section{MATERIALS AND METHODS}

Reagents. Bacteriological agar, casein peptone, and yeast extract powder were purchased from Becton Dickinson (Franklin Lakes, NJ, USA). Citric acid hydrate, D-(+)glucose anhydrous, sodium dodecyl sulfate (SDS), sodium dihydrogen phosphate anhydrous, sodium hydroxide, 3(4,5-dimethylthiazol-2-yl)-2,5-diphenyltetrazolium bromide (MTT) and carboxymethyl cellulose (CMC, C5678) were purchased from Sigma-Aldrich (St. Louis, MO, USA). Avicel-plus ${ }^{\circledR}$ CM 2159 was obtained from FMC Biopolymers, USA. Roswell Park Memorial Institute (RPMI) 1640 medium, fetal bovine serum (FBS) and penicillin-streptomycin was obtained from Merck Millipore (Burlington, VT, USA).

Preparation of bacterial cellulose nanofibrils. Komagataeibacter hansenii (ATCC 53582) was activated in mannitol broth and cultured statically at $30^{\circ} \mathrm{C}$ for 2 days. The culture was propagated at $30^{\circ} \mathrm{C}$, under stirring, for $24 \mathrm{hr}$, by the inoculation of $3 \%(\mathrm{v} / \mathrm{v})$ from mannitol broth to Hestrin-Schramm (HS) medium (35). Fresh HS medium was then added to the culture, $500 \mathrm{~mL}$ were transferred to glass plates $\left(20 \times 30 \mathrm{~cm}^{2}\right)$ and incubated statically at $30^{\circ} \mathrm{C}$, for additional 10 days. The resulting $\mathrm{BC}$ membranes were cut into small cubes, placed for 2 days in $4 \%(\mathrm{w} / \mathrm{v}) \mathrm{NaOH}$ solution and then washed with distilled water for 7 days. $\mathrm{BC}$ was then placed in $500 \mathrm{~mL}$ of $2 \%$ (w/v) SDS solution for $12 \mathrm{hr}$ for endotoxin removal. This step was repeated and then $\mathrm{BC}$ cubes were washed with distilled water for 2 days. Before use, $\mathrm{BC}$ cubes were autoclaved $\left(121^{\circ} \mathrm{C}, 15 \mathrm{~min}\right)$ and stored at $4^{\circ} \mathrm{C}$.

$\mathrm{BC}$ nanofibrils were obtained by disintegration of the BC cubes using a laboratory blender Vitamix (Vita Prep 3, Bras Sulamericana) operated at $24000 \mathrm{rpm}$ for $30 \mathrm{~min}$. The fibrillated suspension with a fiber content of $4.77 \mathrm{mg} /$ $\mathrm{mL}$ was diluted to a concentration of $2 \mathrm{mg} / \mathrm{mL}$ and then processed again with the Vitamix blend during $30 \mathrm{~min}$ with (nBCMC) or without (nBC) $0.2 \%(\mathrm{w} / \mathrm{v})$ carboxymethyl cellulose (CMC). The nBCMC suspensions were autoclaved at $121^{\circ} \mathrm{C}$ for $15 \mathrm{~min}$ while $\mathrm{nBC}$ suspensions were sterilized by $\gamma$ irradiation ( $25 \mathrm{kGy}$ for 3 days, corresponding to $0.35 \mathrm{kGy} / \mathrm{hr}$ ), since the nanofibers without $\mathrm{CMC}$ were not colloidally stable at higher temperature.

Endotoxin quantification. Endotoxin concentration $(\mathrm{EU} / \mathrm{mL})$ in the samples was determined with the Pierce LAL Chromogenic Endotoxin Quantitation Kit (Thermo Fisher Scientific, Waltham, MA, USA) according to the manufacturer's instructions. Bacterial endotoxin catalyses the activation of a proenzyme in the modified Limulus Amebocyte Lysate (LAL) which catalyses the splitting of $p$-Nitroaniline $(p \mathrm{NA})$ from the colorless substrate. The released $p$ NA was photometrically measured at $410 \mathrm{~nm}$.

\section{Characterization of bacterial cellulose nanofibrils.}

- Transmission electron microscopy (TEM): The colloidal suspension of cellulose nanofibrils was spread in a 300-mesh grid for $10 \mathrm{~min}$. Then, the sample excess was removed carefully with a filter paper and thereafter, one drop of a $1 \%(\mathrm{w} / \mathrm{v})$ phosphotungstic acid solution was added. After $30 \mathrm{sec}$, the excess was removed with filter paper and the samples were analyzed with a Scanning Electron Microscope (SEM) (Vega3, Tescan, Brno, Czech Republic) equipped with a Scanning Transmission Electron Microscopy detector (STEM) (Tescan).

- Zeta potential: The zeta potential of cellulose nanofibrils suspensions was estimated by Dynamic Light Scattering (DLS) using a Zetasizer NanoZS, (Malvern Instruments Ltd., Worcestershire, UK). Three measurements of each suspension were performed and the zeta potential values were determined using Henry's equation (36).

- X-ray diffraction (XRD): XRD patterns of the lyophilized cellulose nanofibrils samples were performed in an X-ray diffractometer (D/MAX-B, Rigaku Americas Corporation, The Woodlands, TX, USA), using a copper $\mathrm{Cu}$ tube and $\mathrm{Ka}$ radiation. Samples were examined with a scanning angle of $2 \theta$ values from $5^{\circ}$ to $50^{\circ}$ at a rate of $0.5^{\circ} \mathrm{min}$. The crystalline index was determined using the method described by (37).

\section{In vitro assays.}

- Culture of murine bone marrow-derived macrophages: Mouse bone marrow-derived cells (BMMФ) were differentiated in vitro according to previous reported methods with some modifications (38). C57BL/6 mice were anesthetized using a $\mathrm{CO}_{2}$ chamber and euthanized by cervical dislocation. Femurs and tibias were removed and cleaned in aseptic conditions. Bones were disconnected by the articulations and then flushed using $5 \mathrm{~mL}$ of Roswell Park Memorial Institute (RPMI) 1640 Medium (Merck Millipore, Burlington, VT, USA) supplemented with 10\% fetal bovine serum (FBS) and 1\% Penicillin-Streptomycin (complete media). The obtained cell suspension of bone marrow cells was centrifuged ( $300 \mathrm{~g}, 10 \mathrm{~min})$ and the pellet re-suspended in $10 \mathrm{~mL}$ of complete RPMI supplemented with 20\% L929-cell conditioned medium (LCCM). Cells were allowed to differentiate into macrophages for 7 days, at $37^{\circ} \mathrm{C}$ in a $5 \% \mathrm{CO}_{2}$ atmosphere, in 6-well plates, at a density of $1 \times 10^{6}$ cells $/ \mathrm{mL}$. At day 4 , culture media were removed and replaced with fresh complete differentiation medium. At day 7, differentiated cells were scraped and seeded at the desired concentration in 96-well plates. 
- MTT reduction assay: ВММФ and mouse fibroblast L929 cells were seeded in 96-well plates at a density of $5 \times 10^{5}$ and $2 \times 10^{5}$ cells/well, respectively, and allowed to adhere overnight at $37^{\circ} \mathrm{C}$ in a $5 \% \mathrm{CO}_{2}$ atmosphere. Then, cells were incubated for $24 \mathrm{hr}$ in the presence 0.02 and $0.2 \mathrm{mg} / \mathrm{mL}$ ( 1 and $10 \mu \mathrm{g}$, respectively) of $\mathrm{nBC}, \mathrm{nBCMC}$ in a final volume of $200 \mu \mathrm{L} /$ well. Phosphate-buffered saline (PBS, pH 7.4) was added to the negative control. Cells were also exposed to equal doses of microcrystals obtained from Avicel-plus ${ }^{\circledR}$ CM 2159 (FMC Corporation, Philadelphia, PA, USA), a plant-derived cellulose, used for comparison. On the following day, cell culture media was removed and cells' metabolic viability was assessed by measuring the reduction of the tetrazolium salt MTT. Briefly, $50 \mu \mathrm{L}$ of $1 \mathrm{mg} / \mathrm{mL}$ MTT (Sigma-Aldrich) was added per well and the plate was further incubated for $2 \mathrm{hr}$ at $37^{\circ} \mathrm{C}$ protected for light. In the end, MTT solution was removed and isopropanol added ( $100 \mu \mathrm{L} /$ well) to solubilize formazan. Absorption was then determined spectrophotometrically at 570 $\mathrm{nm}$ in a Bio-Rad Model 680 (Bio-Rad laboratories, Hercules, CA, USA) microplate reader and metabolic activity expressed as percentage relative to the negative control.

In vivo assays. Female $\mathrm{C} 57 \mathrm{BL} / 6$ mice were acquired from Charles River Laboratories (Barcelona, Spain) and, upon arrival at the animal facility of Biomedical Sciences Institute Abel Salazar, separated randomly into groups. Mice were housed in individually-ventilated cages and handled in a laminar flow hood cabinet. Each mouse group was given food and water ad libitum. Prior to treatment administration, each mouse was anesthetized with an intraperitoneal (i.p.) injection of ketamine $(100 \mathrm{mg} / \mathrm{kg}$ ) (Merial, Lyon, France) and xylazine $(10 \mathrm{mg} / \mathrm{kg}$ ) (Bayer, Leverkusen, Germany). Three groups of animals (5 mice per group) were exposed to $50 \mu \mathrm{L}$ of nBCMC at the following doses: $0.04,0.4$ and $4 \mathrm{mg} / \mathrm{kg}$ (equivalent to 1,10 and $100 \mu \mathrm{g}$ of fibers, respectively) via intratracheal administration using a Microsprayer ${ }^{\circledR}$ Aerosolizer system (Microsprayer ${ }^{\circledR}$ Aerosolizer-Model IA-1C, Penn Century, Wyndmoor, PA, USA) coupled to an FMJ-250 High Pressure Syringe (Penn Century, Wyndmoor, PA, USA). The different doses of nBCMC used in this study were selected since we intended to assess the effect of the fibers in the lungs using from very small $(0.02 \mathrm{mg} / \mathrm{mL}, 1 \mu \mathrm{g})$ up to very high $(2 \mathrm{mg} / \mathrm{mL}, 100 \mu \mathrm{g})$ concentrations.

Fifty microliters of PBS or $0.2 \% \mathrm{CMC}$ (referred as $\mathrm{CMC}_{100}$ and representing an amount of $100 \mu \mathrm{g}$ ) were administered to two groups of animals used as controls. After different time points, animals were euthanized by i.p. administration of a lethal dose of ketamine and xilazine and bronchoalveolar lavage (BAL) collected as detailed in subsection 2.6. For pulmonary toxicity assessment, mice were divided into different treatments groups, represented in supplementary Table 1. Fig. 1 shows the treatment strategy. Animals were administered with $50 \mu \mathrm{L}$ of either $100 \mu \mathrm{g}$ of nBCMC $\left(\mathrm{nBCMC}_{100}\right), 100 \mu \mathrm{g}$ of Avicel-plus ${ }^{\circledR}$ CM 2159

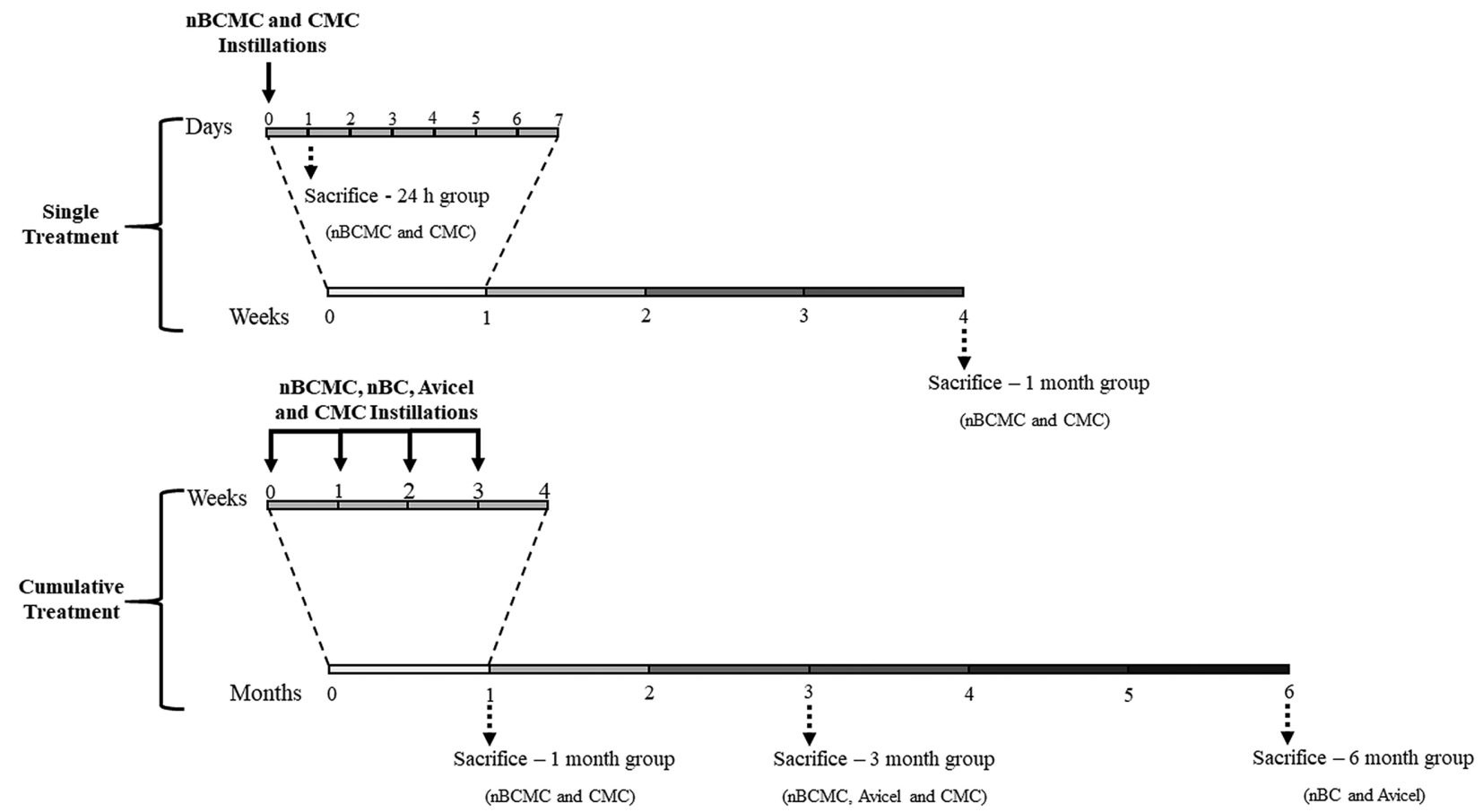

Fig. 1. Scheme of intratracheally instillations of C57BL/6 mice with $n B C M C, n B C, C M C$ and Avicel-plus ${ }^{\circledR} C M 2159$ and respective group sacrifice/analysis time points. 
(Avicel ${ }_{100}$ ) or $100 \mu \mathrm{g}$ of $\mathrm{nBC}\left(\mathrm{nBC}_{100}\right)$. Control groups comprising mice treated with $50 \mu \mathrm{L}$ of PBS or $\mathrm{CMC}_{100}$ were also performed. All the procedures involving mice were performed according to the European Convention for the Protection of Vertebrate Animals used for Experimental and Other Scientific Purposes (ETS 123) and directive 2010/63/EU of the European parliament and of the council of 22 September 2010 on the protection of the animals used for scientific purposes, and Portuguese rules (DL 113/2013). Experiments were approved by the institutional board responsible for animal welfare at ICBAS (109/2015) and by the competent national board authority, Directorate-General of Food and Veterinary Medicine (0421/000/000/2015).

Collection of bronchoalveolar lavage fluids (BAL). At defined time-points, mice were euthanized, the trachea was exposed and a small incision made below the larynx. A catheter was inserted and secured with a suture thread and the tissue washed three times with $500 \mu \mathrm{L}$ of PBS. The efficacy of the BAL fluid collection ranged from 80 to $90 \%$ of total volume injected. The first two lavages were centrifuged at $2000 \mathrm{rpm}$ (Eppendorf Centrifuge $5430 \mathrm{R}$ ) for $10 \mathrm{~min}$ at $4^{\circ} \mathrm{C}$. The supernatant was later aliquoted and stored at $-20^{\circ} \mathrm{C}$ for marker analysis and the recovered cells were counted and used for flow cytometry analysis. Samples presenting blood contamination were rejected.

Flow cytometry. Flow cytometry analysis of BAL recovered cells was performed by suspending the cells in PBS containing $1 \%$ BSA and $10 \mathrm{mM}$ sodium azide (FACS buffer) and blocking unspecific antibody binding by preincubation with anti-Fc $\gamma \mathrm{R} \mathrm{mAb}$. Cell staining was performed by incubation with anti-mouse CD19 fluorescein isothiocyanate-conjugate (clone 1D3), anti-mouse CD11b Phycoerythrin-conjugate (clone M1/70) (both from BD biosciences, San Diego, CA, USA), anti-mouse F4/80 Phycoerythrin-cychrome 5.5-conjugate (clone BM8) (eBioscience, San Diego, CA, USA) and anti-mouse Ly6G Allophycocyanin-conjugate (clone 1A8), anti-mouse CD11c brilliant violet 421-conjugate (clone N418) and anti-mouse CD3 brilliant violet 510-conjugate (clone 17A2) (all from Biolegend, San Diego, CA, USA) mAb. Dead cells were excluded from the analysis following staining with fixable viability dye Allophycocyanin-eflour 780-conjugate (eBioscience). Antibody-labelled cells were detected in an FACS Canto II using FACS Diva software (BD biosciences, San Diego, CA, USA). At least 100000 events were acquired per sample. The collected data files were analyzed using FlowJo X 10.0.7r2 (Tree Star inc., Ashland, OR, USA).

\section{Cytotoxic and oxidative stress marker analysis in BAL fluids.}

- Protein quantification: Total protein concentration in the BAL was determined using a microBCA Protein
Assay kit (Pierce, Rockford, IL, USA), according to the manufacturer's instructions. Briefly, samples were diluted in micro BCA working reagent and incubated at $37^{\circ} \mathrm{C}$ for $2 \mathrm{hr}$. Absorbance was measured at $562 \mathrm{~nm}$ and protein concentration expressed as $\mu \mathrm{g} / \mathrm{mL}$. Increase in the protein concentration in BAL fluid is considered a measure of increased permeability of alveolar-capillary barriers.

- Lactate dehydrogenase (LDH) release: Pulmonary damage following treatment was assessed by measurement of LDH release. LDH is a strictly intracellular enzyme, and its presence outside of cells indicates compromised cell membrane and consequently cell death. Quantification of LDH release was performed in BAL using Pierce LDH Cytotoxicity Assay Kit (Thermo Fisher Scientific) following the manufacturer's instructions. Samples were diluted in an assay buffer and combined with $\mathrm{NAD}^{+}$, lactic acid, tetrazolium salt, and diaphorase. Briefly, extracellular LDH catalyzes the conversion of lactate to pyruvate via $\mathrm{NAD}^{+}$reduction to NADH. Diaphorase then uses NADH to reduce a tetrazolium salt to a red formazan product. Absorbance was read at $490 \mathrm{~nm}$ and results expressed as percentage of LDH release relatively to control after subtracting the absorbance values at $680 \mathrm{~nm}$ (background signal).

- Hydrogen peroxide $\left(\mathrm{H}_{2} \mathrm{O}_{2}\right)$ quantification: Levels of $\mathrm{H}_{2} \mathrm{O}_{2}$, a reactive oxygen species that contributes to oxidative stress and therefore cell damage when produced abnormally, were measured using the Fluorimetric hydrogen Peroxide assay kit (Sigma-Aldrich) following the manufacturer's instructions. Briefly, BAL samples were diluted in assay buffer combined with horseradish peroxidase and peroxidase. The peroxidase substrate generates an infra-red fluorescent product after reaction with hydrogen peroxidase. Fluorescence intensity was measured at $\lambda_{\text {ex }}=640 / \lambda_{\text {em }}=680$ and $\mathrm{H}_{2} \mathrm{O}_{2}$ concentration, expressed as $\mu \mathrm{M}$, calculated after interpolating the samples' fluorescence values from a standard calibration curve.

- Quantification of total glutathione (GSH): Glutathione (GSH), a tripeptide ( $\gamma$-glutamylcysteinylglycine) that is an essential electron donor to glutathione peroxidase in the reduction of hydroperoxides was determined in BAL using the biochemical assay Glutathione assay kit (Cayman Chemical, Ann Arbor, MI, USA) according to the manufacturer's instructions. Briefly, GSH was analyzed following a $1: 1$ dilution of the BAL fluid sample in MES buffer (2×) [0.4 M 2-(N-morpholino)ethanesulfonic acid, $0.1 \mathrm{M}$ phosphate, and $2 \mathrm{mM}$ EDTA (pH 6.0)] containing NADP ${ }^{+}$, glucose-6-phosphatase, glutathione reductase, glucose-6-phosphate dehydrogenase and 5,5'-dithiobis-(2-nitrobenzoic acid) (DTNB). The sulfhydryl group of GSH reacts with DTNB leading to the production of a yellow colored 5-thio-2-nitrobenzoic acid (TNB). The mixed disulfide GSTNB (between GSH and TNB) formed is reduced by glutathione reductase to $\mathrm{GSH}$, a reaction that 
produce more TNB. The rate of TNB production is directly proportional to this recycling reaction, which in turn is directly proportional to the concentration of GSH in the sample. GSH concentration, expressed as $\mu \mathrm{M}$, was determined after measuring the absorbance of the samples at $405 \mathrm{~nm}$ and interpolation from a standard calibration curve.

- Glutathione peroxidase (GPX) activity: Activity of GPx, an antioxidant enzyme that catalyses the reduction of hydroperoxides by reduced glutathione, was determined in BAL using the Glutathione Peroxidase Assay Kit (Cayman Chemical) through an indirect coupled reaction with glutathione reductase. Oxidized gluta- thione produced upon reduction of hydroperoxide by GPx is recycled to its reduced state by glutathione reductase and NADPH. Absorbance was measured at $340 \mathrm{~nm}$ and a decrease in the absorbance is directly proportional to the GPx activity (expressed as $\mathrm{nmol} / \mathrm{min} / \mathrm{mL}$ ) in the sample.

- Lipid peroxidation: Lipid peroxidation, an indicator of cellular damage and oxidative stress, was measured using the TBARS Assay Kit (Cayman Chemical) according to manufacturer's instructions. Specifically, levels of thiobarbituric acid reactive substances (TBARS) were quantified by measuring the absorbance of malondialdehydethiobarbituric acid (MDA-TBA) adducts in BAL fluid samples at $532 \mathrm{~nm}$. The MDA-TBA adducts were formed by the reaction of MDA and TBA under high temperature $\left(100^{\circ} \mathrm{C}\right)$ via acid hydrolysis.

- Myeloperoxidase activity: Myeloperoxidase (MPO) is an enzyme that is released upon neutrophils stimulation and therefore serves as an index of neutrophil infiltration (39). MPO was quantified in BAL using the Neutrophil Myeloperoxidase Activity Assay Kit (Cayman Chemical) according to the manufacturer's instructions. Briefly, samples were diluted in assay buffer and 3,3',5,5'-tetramethylbenzidine (TMB), which reacts with MPO yielding a blue color detectable by its absorbance at $650 \mathrm{~nm}$. Plate was incubated for $10 \mathrm{~min}$ at room temperature and then absorbance was read.

Tissue sample and histopathological analysis. The lungs, heart and liver were fixated in $10 \%$ neutral buffered formalin and routinely processed. Slides were H\&Estained for histological analysis, following the International Harmonization of Nomenclature and Diagnostic Criteria for Lesions in Rats and Mice (INHAND) guidelines for respiratory tract lesions (40).

Statistical analysis. Statistical analysis was performed using GraphPad Prism 5 (GraphPad Software, San Diego, CA, USA). Results were expressed as mean \pm SD. Normality of the distributions was examined prior to each analysis using Kolmogorov-Smirnov normality tests, and taking into account the acceptability of skewness and kurtosis values. According to the results from the normality tests, one-way ANOVA, followed by Bonferroni's multiple comparison post-test or Dunnett's Multiple Comparison Test was performed wherever appropriate.

\section{RESULTS}

Characterization of cellulose nanofibrils suspension. As shown in Table 1, BC nanofibrils obtained by the blending process herein described have a negative surface charge $(-9.8 \mathrm{mV})$. This result is in agreement with previous reports that described a zeta potential of $-16.9 \mathrm{mV}$ for fibrillated BC (41). Following sterilization by autoclaving, agglomeration of the nanofibrils in suspension occurred. This is an expected effect since the BC nanofibrils suspension presents a fairly low surface charge $(<|30 \mathrm{mV}|)$ and therefore poor colloidal stability (42). To obtain a stable and homogeneous solution after autoclaving, 0.2\% CMC was added to the $\mathrm{BC}$ nanofibrils. As observed in Table 1, nBCMC presented an even more negative surface charge $(-62.8 \mathrm{mV})$, compared to $\mathrm{nBC}$. After sterilization, the nBCMC nanofibrils suspension indeed remained stable and homogeneous.

The crystallinity analysis of $\mathrm{nBC}$ presented the characteristic diffraction pattern of cellulose I, similar to those reported in the literature for $\mathrm{BC}$ (43), corresponding to a crystallinity index (CI) of 75\% (Table 1). nBCMC presented a slightly lower CI (69\%) (Table 1). Regarding nanofibrils morphology, results showed that $\mathrm{nBC}$ has an average width of $43.0 \pm 16.5 \mathrm{~nm}$ (Fig. 2A, Table 1). The $\mathrm{nBCMC}$ nanofibrils presented a width of $47.0 \pm 19.5 \mathrm{~nm}$ (Fig. 2B, Table 1), which was not significantly different from $\mathrm{nBC}$.

Endotoxin quantification. The potential presence of endotoxins, which include lipid A, a glucosamine-based phospholipid found in the outer monolayer of the outer membranes of most Gram-negative (44), is one of the main concerns when using materials of microbial origin for biomedical applications. Indeed, the presence of bacterial endotoxins in biomedical products may produce fever, septic shock and even death $(45,46)$. The endotoxin quantification obtained in the LAL test is shown in Table 2.

In vitro cytotoxicity caused by the cellulose nanofibers. The in vitro cytotoxicity of different concentrations of cel-

Table 1. Carboxymethyl cellulose and bacterial cellulose suspension properties (crystallinity, zeta potential and nanofibrils width)

\begin{tabular}{lccc}
\hline \hline & $\begin{array}{c}\text { Crystallinity } \\
(\%)\end{array}$ & $\begin{array}{c}\text { Zeta potential } \\
(\mathrm{mV})\end{array}$ & $\begin{array}{c}\text { Nanofibrils width } \\
(\mathrm{nm})\end{array}$ \\
\hline $\mathrm{nBC}$ & 75 & $-9.8 \pm 0.4$ & $43 \pm 16.5$ \\
$\mathrm{nBCMC}$ & 69 & $-62.8 \pm 1.5$ & $47 \pm 19.5$ \\
\hline
\end{tabular}




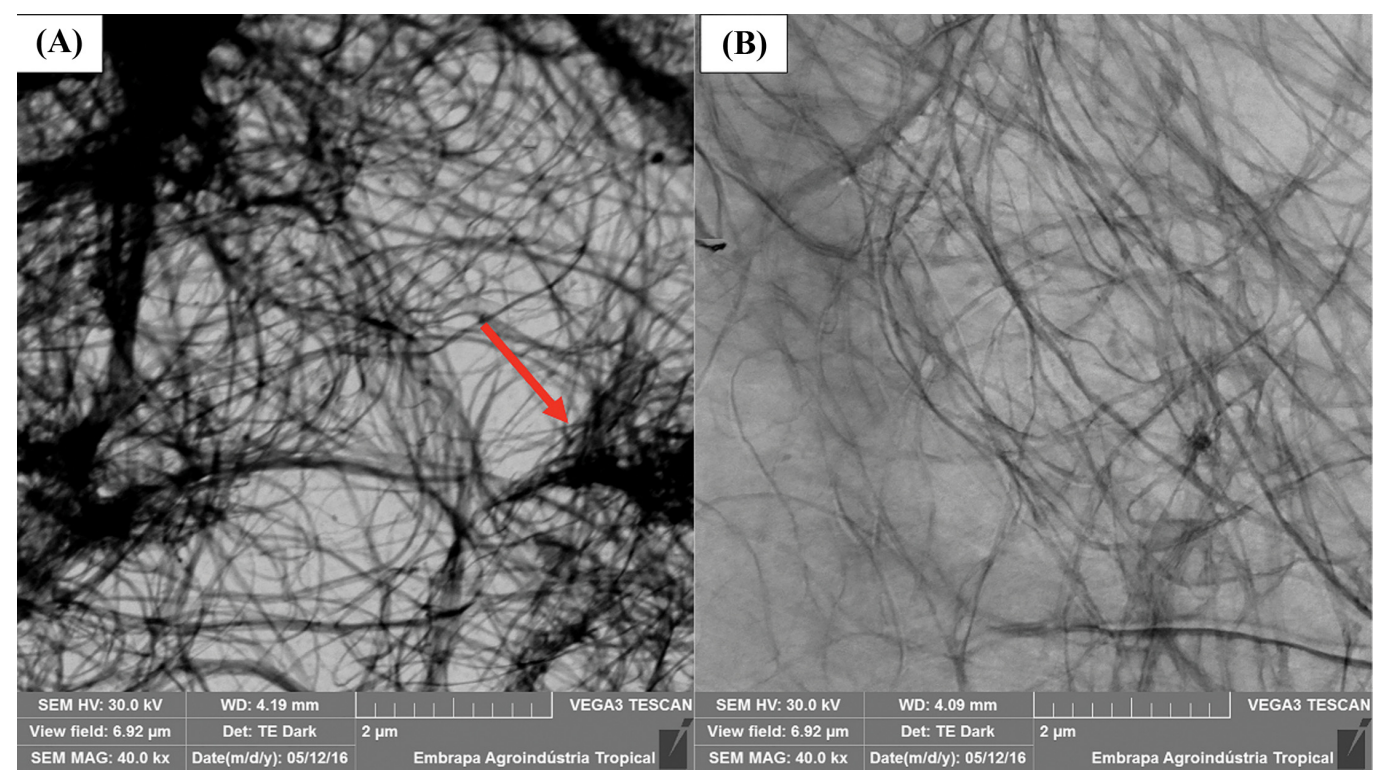

Fig. 2. TEM micrograph of $(A) n B C$ and $(B) n B C M C$ after thermal sterilization. The red arrow indicates nanofibrils bundles that were not observed in the presence of $\mathrm{CMC}_{100}$.

Table 2. Endotoxin levels measured in $\mathrm{CMC}, \mathrm{nBCMC}, \mathrm{nBC}$ and a cellulose sample from vegetable origin

\begin{tabular}{lc}
\hline \hline Material & [Endotoxins] $(\mathrm{EU} / \mathrm{mL})$ \\
\hline $\mathrm{nBC}$ & 0.05 \\
nBCMC $^{*}$ & 0.7 \\
Avicel-plus ${ }^{\circ} \mathrm{CM} 2159$ & 0.5 \\
\hline
\end{tabular}

${ }^{*} \mathrm{nBCMC}$ is $\mathrm{nBC}$ containing $0.2 \% \mathrm{CMC}$. Endotoxin level of $\mathrm{CMC}$ was $0.8 \mathrm{EU} / \mathrm{mL}$.

lulosic materials was evaluated by measuring the metabolic viability of BMMФ from C57BL/6 mice. Results in Fig. 3 show that neither $\mathrm{nBC}$ nor $\mathrm{nBCMC}$ affected the metabolic activity, after $24 \mathrm{hr}$ exposure. A significant increase in metabolic viability was obtained after treatment with $10 \mu \mathrm{g}$ of $\mathrm{nBC}$ and $1 \mu \mathrm{g}$ of $\mathrm{nBCMC}$, an effect that was previously observed by others when exposing macrophages to plant cellulose $(47,48)$.

Assessment of acute toxicity. Bacterial cellulose is normally regarded as a "biocompatible" material (49). However, dose-dependent cytotoxic effects and pulmonary damage were observed in mice treated with cellulose nanocrystals of plant origin (34). To assess putative toxic effects of nBCMC, mice were exposed to different doses of this material via intratracheal administration and pul-
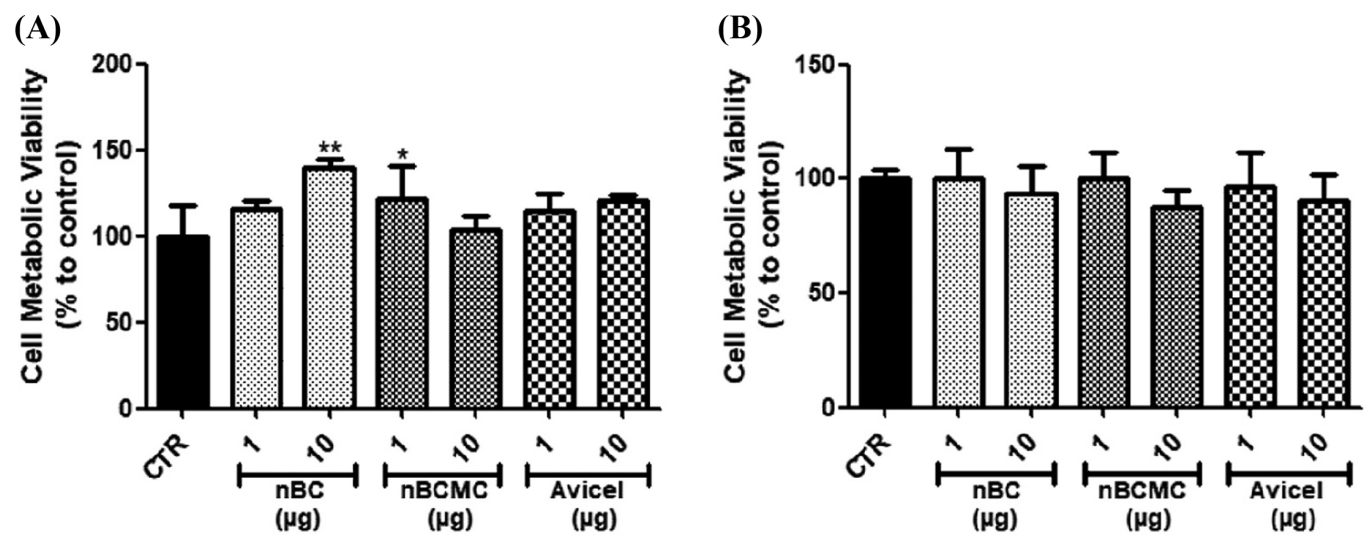

Fig. 3. Metabolic viability of the (A) BMM $\Phi$ and (B) L929 cells after treatment with different cellulosic materials assessed by MTT assay. BMMФ and $L 929$ cells were exposed to increasing doses of $\mathrm{nBC}, \mathrm{nBCMC}$ and Avicel (1 and $10 \mu \mathrm{g}$ ) for $24 \mathrm{hr}$. In addition, cells were treated with PBS (control). Data is expressed as percentage relative to the control and presented as mean \pm SD of three independent experiments. All the treatment conditions were compared with the control using the Dunnett's Multiple Comparison Test. ${ }^{*} p<0.05$ and ${ }^{* *} p<0.01$, compared to control (non-treated cells). 
(A)

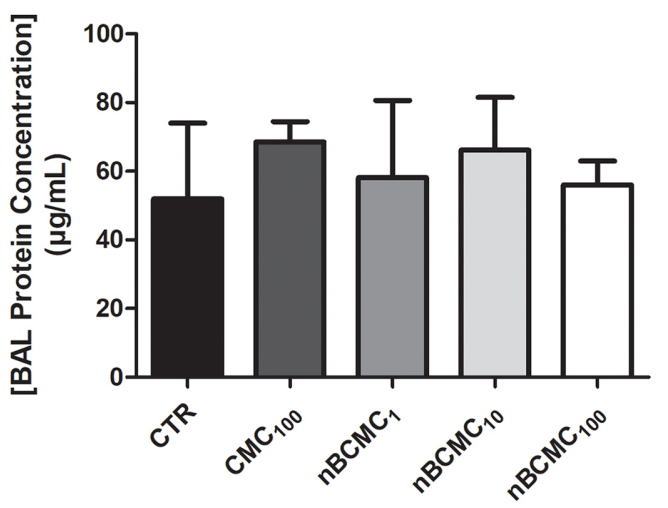

(B)

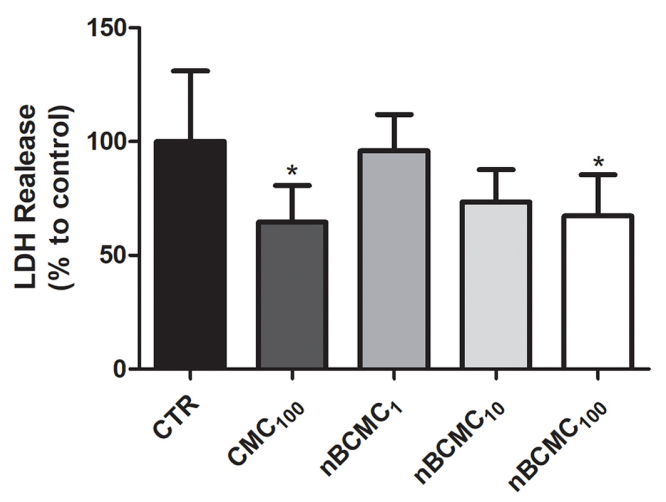

Fig. 4. Quantification of (A) total protein and (B) $L D H$ release in the BAL samples after $24 \mathrm{hr}$ treatment with different dosages of nBCMC. ${ }^{*} p<0.05$ comparing $\mathrm{CMC}_{100}$ and $\mathrm{nBCMC} 100 \mu \mathrm{g}$ to control.

monary damage or inflammation was assessed by quantifying soluble markers in the BAL or by lung histological analysis. Dysfunction of the air-blood barrier has been identified as a sign of acute lung injury (50) and can be assessed by the total protein measurement in BAL as increased permeability or damage of the air-blood barrier may cause transudation of serum proteins into the fluid of the lungs (51). As shown in Fig. 4A, no significant differences in BAL total protein content were found between control and treated groups or among the different treated groups, $24 \mathrm{hr}$ after instillation. Moreover, as shown in Fig. $4 \mathrm{~B}$, the different treatment dosages did not increase lac- tate dehydrogenase (LDH) release to the BAL, an indicator of acute toxicity to lung cells promoted by inhaled substances (52). Actually, LDH levels in BAL fluids of mice treated with $\mathrm{CMC}_{100}$ or $\mathrm{nBCMC}_{100}$ were lower than in the control group. Despite indicators of inflammation were not detected elevated in the BAL, histological analysis of the lungs nevertheless showed that mice exposed to 1,10 and $100 \mu \mathrm{g}$ of $\mathrm{nBCMC}$ and CMC presented a mild diffuse degeneration of terminal bronchioles, characterized by epithelial blabbing and cytoplasmic vacuolization, and a mild multifocal to coalescing acute bronchioalveolar inflammation (Fig. 5). The inflammatory infiltrate was
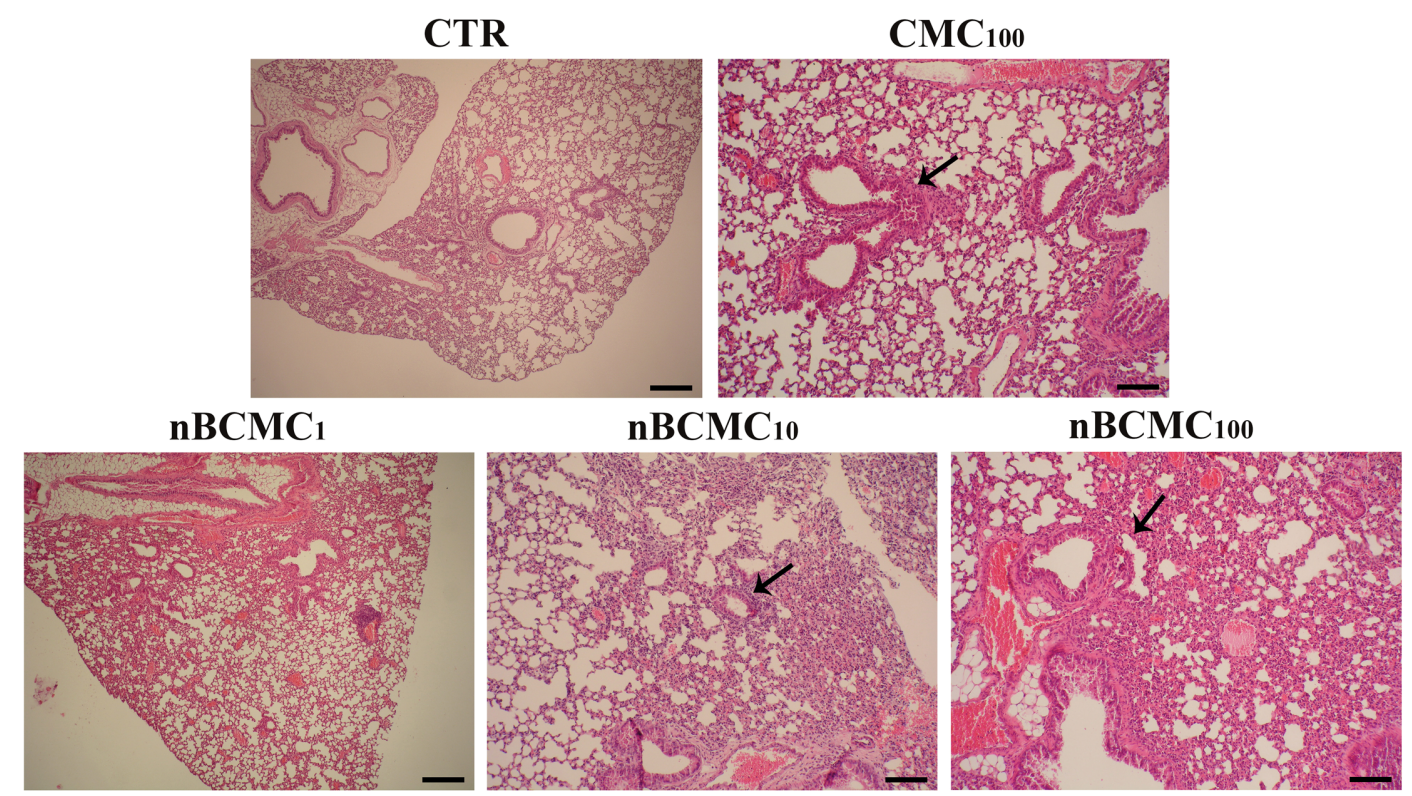

Fig. 5. Mice lung sections after $\mathrm{CMC}_{100}$ and $\mathrm{nBCMC}_{1,10}$ and ${ }_{100}$ treatments during $24 \mathrm{hr}$ (40x magnification, scale bar $=200 \mu \mathrm{m}$ ). Treated groups presented mild diffuse degeneration of terminal bronchioles and mild multifocal to coalescing acute bronchioloalveolar inflammation, composed of neutrophils and macrophages that surround terminal bronchioles and occupy adjacent alveoli (arrows). Control groups presented normal lung histology. 
composed of neutrophils and macrophages that infiltrate the terminal bronchiolar walls. Scattered neutrophils and macrophages were present in bronchiolar lumina, alveolar ducts and alveoli. These results altogether indicate that a single intratracheal challenge with $\mathrm{nBCMC}$ or $\mathrm{CMC}$ induced mild inflammatory effects in the mouse lungs.

Assessment of nBCMC pulmonary cytotoxicity and oxidative stress. The lungs are the principal route into the human body for airborne particles often described as
(A)

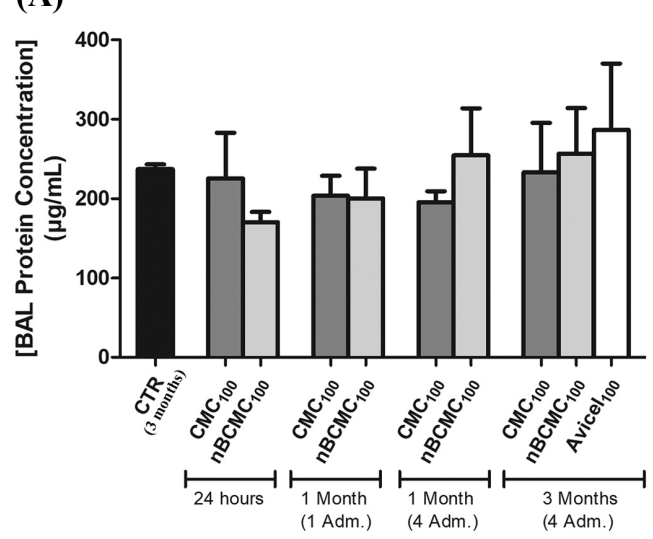

(C)

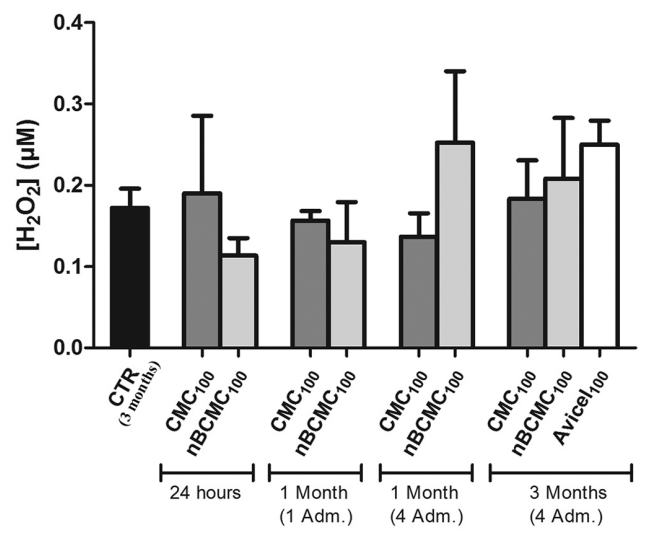

(E)

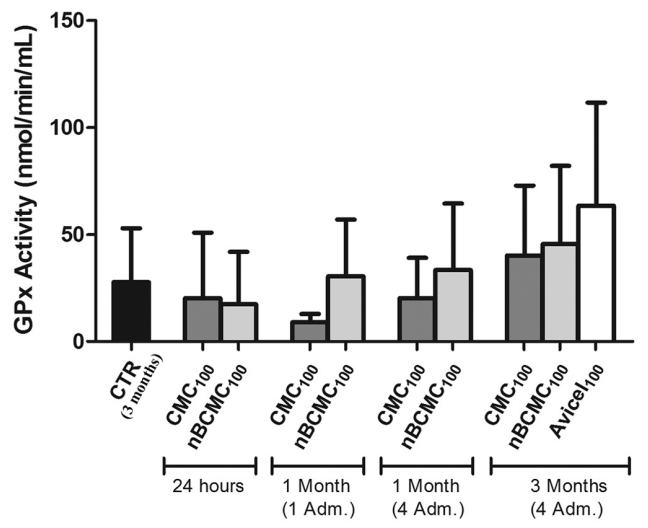

(B)

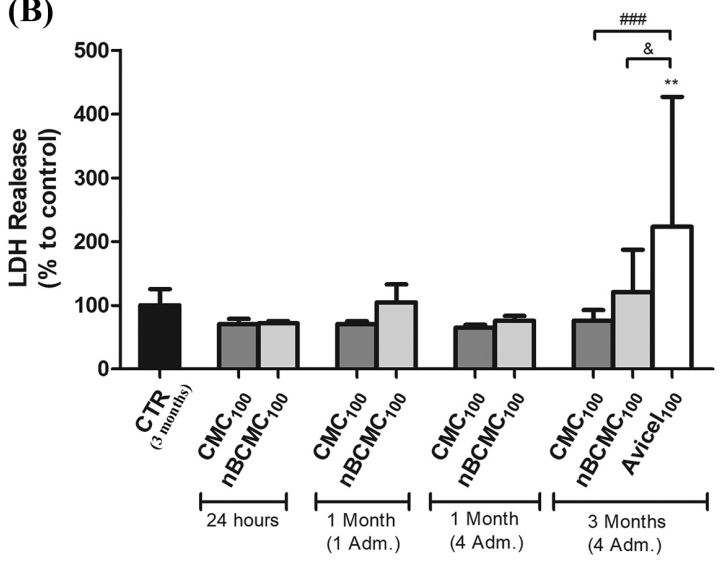

(D)

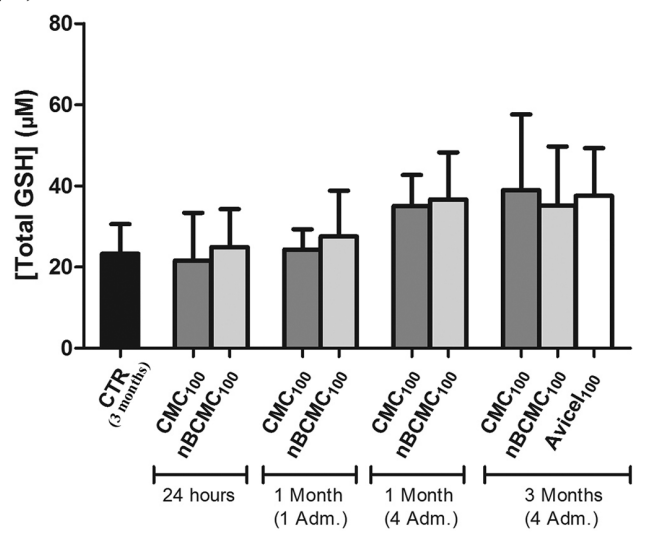

(F)

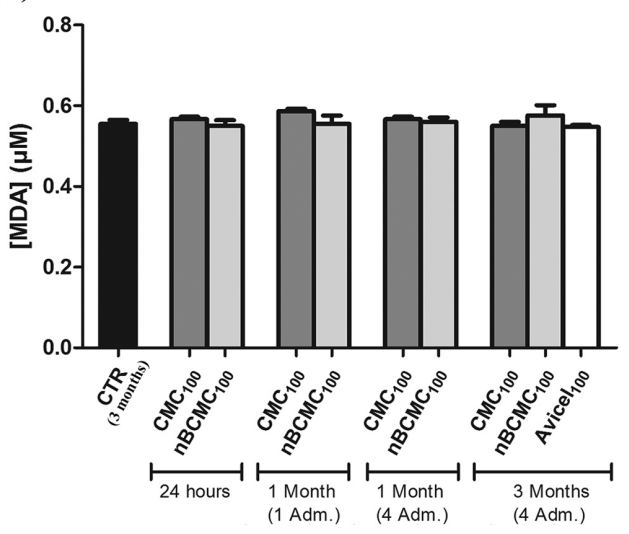

Fig. 6. Assessment of lung damage and oxidative stress responses in BAL fluid of C57BL/6 mice intratracheally instilled with $\mathrm{CMC}_{100}, \mathrm{nBCMC}_{100}$ and Avicel $_{100}$ over time. (A) air-blood barrier damage was evaluated by total protein quantification, ${ }^{* *} p<0.01$, ${ }^{\# \# \# p} p<0.001$ and ${ }^{\&} p<0.05$ comparing Avicel ${ }_{100}$ ( 3 months, $4 \mathrm{adm}$.) with control and with $\mathrm{CMC}_{100}$ ( 3 months, 4 adm.) and $\mathrm{nBCMC}_{100}$ ( 3 months, $4 \mathrm{adm}$.), respectively. The quantification was performed by using calibration curves obtained with the appropriate standards. (B) lung cellular damage was evaluated by LDH release quantification and oxidative stress was measured as (C) $\mathrm{H}_{2} \mathrm{O}_{2}$ (D) total GSH, (E) GPx activity and (F) MDA quantification. Bars correspond to means \pm SD ( $n=3$ or 5 mice per group). 
inducers of lung damage and oxidative stress $(1,34,53,54)$. Mice were treated according to Fig. 1 and Supplementary Table 1, which includes groups treated with a single dose (100 $\mu \mathrm{g} /$ mouse) analyzed after $24 \mathrm{hr}$ and 1 month, and groups treated weekly with 4 cumulative doses $(400 \mu \mathrm{g} /$ mouse) analyzed 1, 3 and 6 months after the first treatment.

Total protein quantification and $\mathrm{LDH}$ released into the BAL (Fig. 6A, 6B) showed no significant differences between the $\mathrm{nBCMC}_{100}, \mathrm{CMC}_{100}$ treatment groups and the control, further indicating that exposure to these materials do not severely damage the air-blood barrier. However, multiple treatments with Avicel $_{100}$ induced a significantly increased release of $\mathrm{LDH}$ comparatively to control, $\mathrm{CMC}_{100}$ and $\mathrm{nBCMC}_{100}$ treatments, as detected 3 months upon the first treatment. This data confirms that the cumulative exposure to the tested plant cellulose nanofibrils promotes cellular damage in the mice lungs, which is in accordance with previous observations made by others $(1,34,55,56)$.
Moreover, no treatment induced significant changes in any of the oxidative stress biomarkers tested (Fig. 6C-6F).

One month after treatment with $\mathrm{nBCMC}_{100}$ mice exhibited identical phenomena as observed $24 \mathrm{hr}$ after exposure, although these also presented multifocal medial hypertrophy of pulmonary arteries (present in 1/6 animals exposed to a single dose and in $3 / 6$ animals exposed to 4 doses), characterized by hypertrophy of smooth muscle in the tunica media, increased connective tissue in the adventitia, presence of visible internal elastic lamina and increased ration of thickness of media/total diameter of intra-acinar arteries (40). After 3 months, $\mathrm{CMC}_{100}$ and Avicel $_{100}$ groups presented mild diffuse degeneration of terminal bronchioles and mild multifocal chronic bronchioloalveolar inflammation, composed of macrophages, lymphocytes and plasma cells, whereas $\mathrm{nBCMC}_{100}$ group showed moderate diffuse degeneration of terminal bronchioles, moderate multifocal to coalescing chronic bronchioloalveolar inflammation, with higher numbers of infiltrating leukocytes and

\section{CTR}

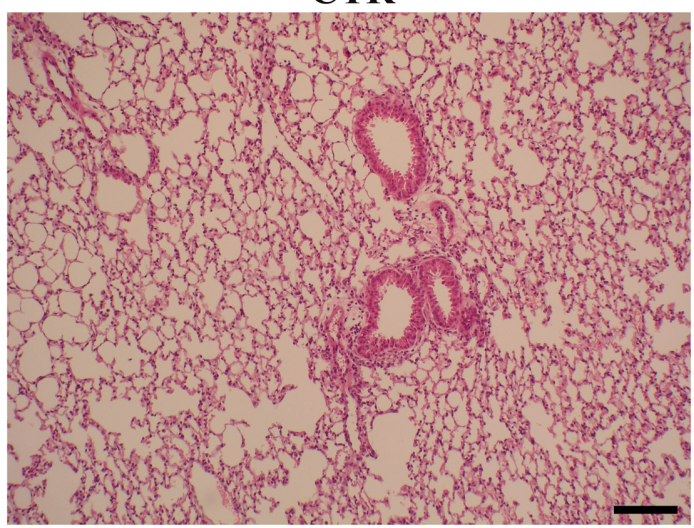

nBCMC100

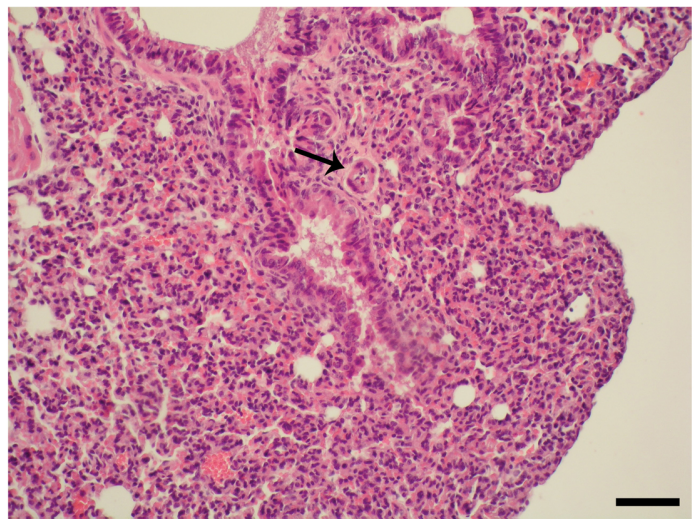

\section{$\mathrm{CMC}_{100}$}

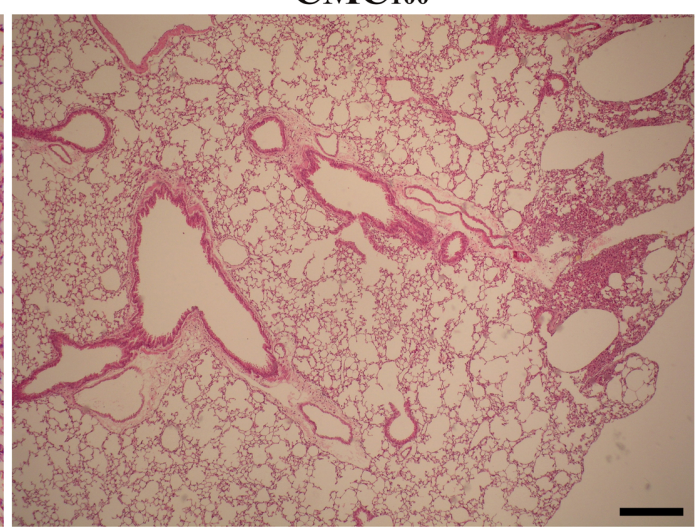

Avicel100

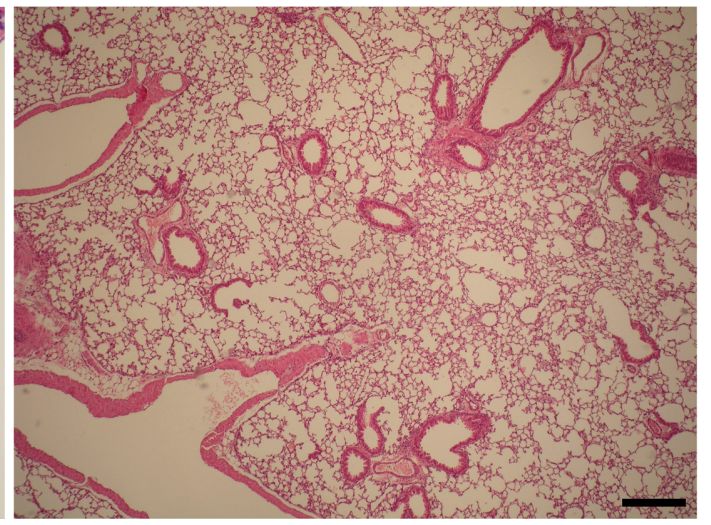

Fig. 7. Mice lung sections after $\mathrm{CMC}_{100}, \mathrm{nBCMC}_{100}$ and Avicel ${ }_{100}$ treatments during 3 months (40x magnification, scale bar $=200 \mu \mathrm{m}$ ). $\mathrm{CMC}_{100}$ and Avicel $_{100}$ groups presented mild diffuse degeneration of terminal bronchioles and mild multifocal chronic bronchioloalveolar inflammation, composed of macrophages, lymphocytes and plasma cells, whereas $\mathrm{nBCMC}_{100}$ group showed moderate diffuse degeneration of terminal bronchioles, moderate multifocal to coalescing chronic bronchioloalveolar inflammation, with higher numbers of infiltrating leukocytes and also multifocal medial hypertrophy of pulmonary arteries (marked with an arrow). Control groups presented normal lung histology. 

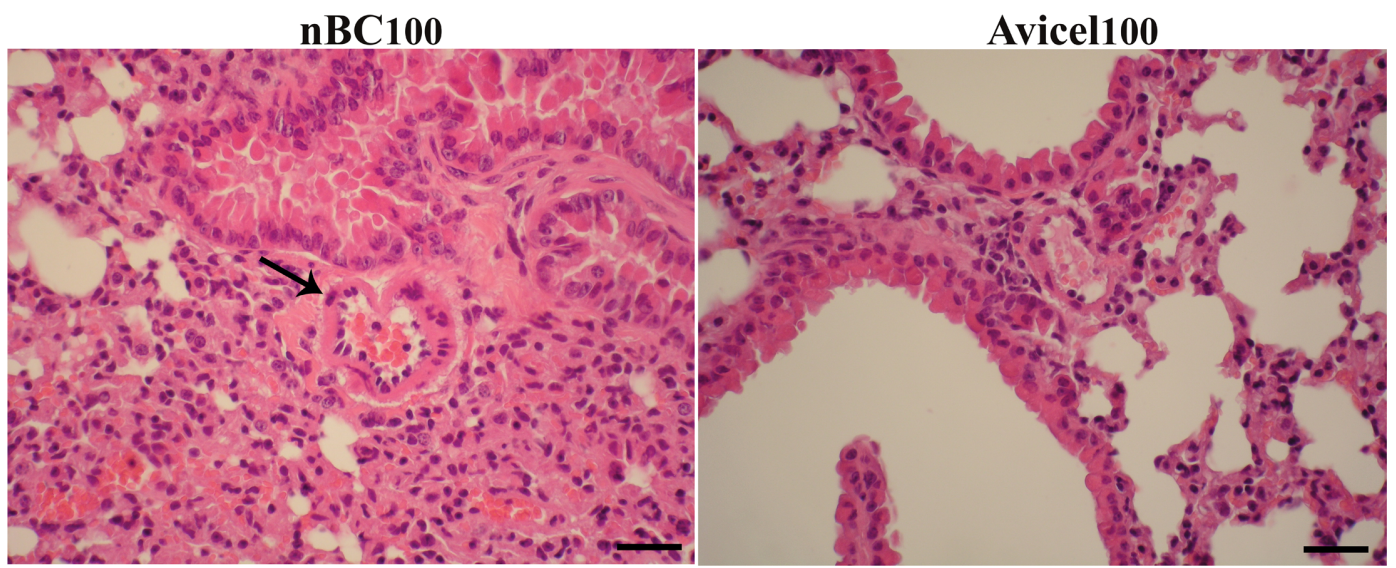

Fig. 8. Mouse lung sections after $\mathrm{nBC}_{100}$ and Avicel $\mathrm{l}_{100}$ treatments during 6 months (400x magnification, $s c a l e=20 \mu \mathrm{m}$ ). $\mathrm{nBC} \mathrm{C}_{100}$ group presented moderate diffuse degeneration of terminal bronchioles, multifocal medial hypertrophy of pulmonary arteries (marked with an arrow) and moderate multifocal to coalescing chronic bronchioloalveolar inflammation, composed of macrophages, lymphocytes and plasma cells, whereas Avicel ${ }_{100}$ group showed mild diffuse degeneration of terminal bronchioles and mild multifocal chronic bronchioloalveolar inflammation with inflammatory infiltrates similar to those observed with $\mathrm{nBC}_{100}$.

Table 3. Summary of the histological alterations observed after the different treatments

\begin{tabular}{lccccc}
\hline \hline \multirow{2}{*}{ Histological findings } & \multicolumn{3}{c}{ Treatments } \\
\cline { 2 - 6 } & \multicolumn{3}{c}{3 months } & \multicolumn{3}{c}{6 months $^{2}$} \\
\cline { 2 - 6 } & $\mathrm{CMC}_{100}$ & $\mathrm{nBCMC}_{100}$ & Avicel $_{100}$ & $\mathrm{nBC}_{100}$ & Avicel $_{100}$ \\
\hline Diffuse degeneration of terminal bronchioles & mild & moderate & mild & moderate & mild \\
\hline Chronic bronchioloalveolar inflammation & mild & $\begin{array}{c}\text { moderate } \\
\text { multifocal to } \\
\text { coalescing }\end{array}$ & mild & $\begin{array}{c}\text { moderate } \\
\text { multifocal to } \\
\text { coalescing }\end{array}$ & mild \\
\hline Multifocal medial hypertrophy of pulmonary arteries & - & & - & & -
\end{tabular}

also multifocal medial hypertrophy of pulmonary arteries (Fig. 7). Animals exposed to multiple Avicel ${ }_{100}$ treatments showed 3 months after the first treatment a mild diffuse degeneration of terminal bronchioles. The presence of multifocal medial hypertrophy of pulmonary arteries $(3 / 6$ animals) was still observed in mice treated with 4 doses of nBCMC $_{100}$ (Fig. 7).

Since CMC alone caused mild diffuse degeneration of terminal bronchioles, which could possibly explain the negative effect induced by nBCMC, we performed another assay in which mice were exposed to 4 doses of $\mathrm{BC}$ fibers without $\mathrm{CMC}\left(\mathrm{nBC}_{100}\right)$ and analyzed 6 months after the first treatment. The extended time point allowed assessing putative cardiac or hepatic hypertension-related lesions. As shown in Fig. 8, animals exposed to nBC also presented moderate diffuse degeneration of terminal bronchioles and, as observed in the previous assay, the presence of multifocal medial hypertrophy of pulmonary arteries (4/ 5 animals) was still observed. Mice treated with Avicel $_{100}$ only showed mild diffuse degeneration of terminal bronchioles, as observed in the previous in vivo assay. Table 3 summarizes the histological findings referred above. Mice of the different groups showed no cardiac or hepatic lesions. These results, observed 3 and 6 months after treatment, may be due to the multifocal (rather than diffuse) distribution of the hypertrophy of pulmonary arteries (in the case of the $\mathrm{nBCMC}_{100}$ and $\mathrm{nBC}_{100}$ group), or because the animal's coping ability was not overcome during the incubation periods. Moreover, none of the treatments induced measurable systemic repercussions over time, since no alterations in the weight of the removed organs was observed. Altogether, the histological results confirmed the hazardous effect of BC nanofibrils inhalation.

Effect of the BC nanofibrils in the recruitment of inflammatory cells to lungs. To assess the effect of $\mathrm{BC}$ nanofibrils exposure in promoting cell recruitment to the broncoalveolar space, the number and proportions of different leukocyte cell populations present in the BAL fluids were assessed by flow cytometry using the gating strategies defined in the Supplementary Fig. 1, in the supplementary material. As shown in Fig. 9A, 9B, higher numbers of neutrophils ( $\mathrm{Ly} 6 \mathrm{G}^{+} \mathrm{CD} 11 \mathrm{~b}^{\text {high }}$ cells) and macrophages $\left(\mathrm{F} 4 / 80^{+} \mathrm{CD} 11 \mathrm{c}^{+} \mathrm{CD} 11 \mathrm{~b}^{\text {int }}\right.$ cells) were detected in 


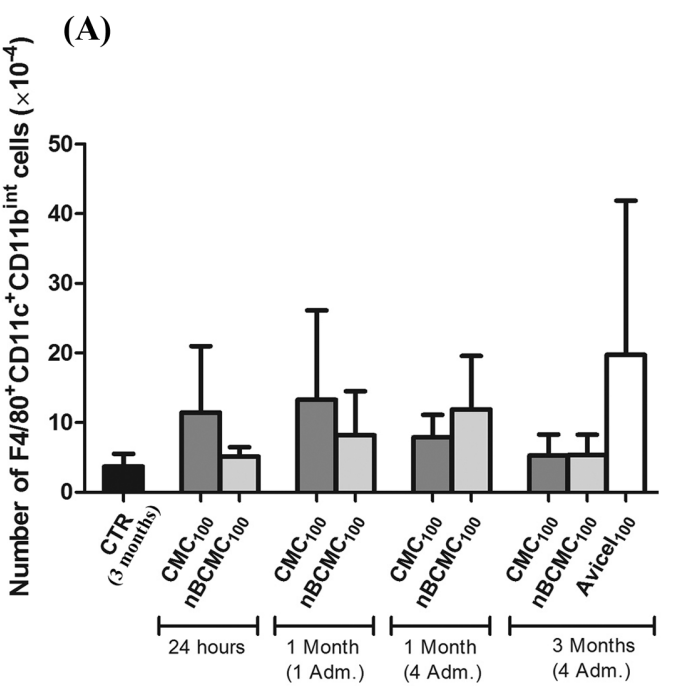

(C)

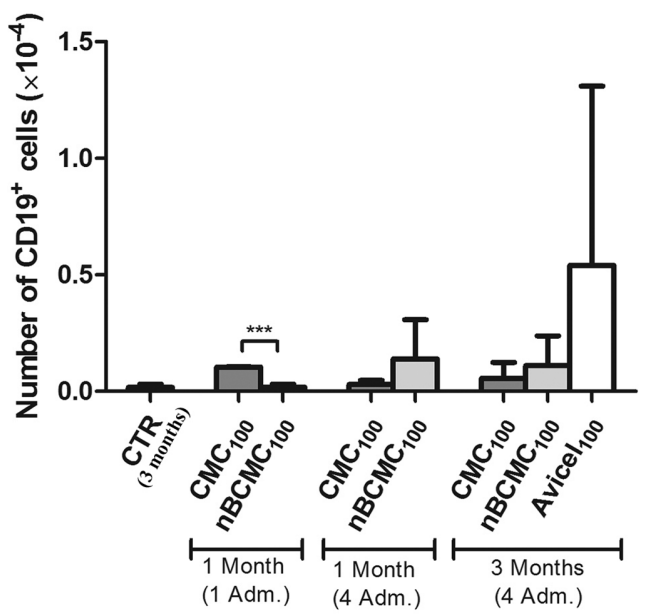

(B)

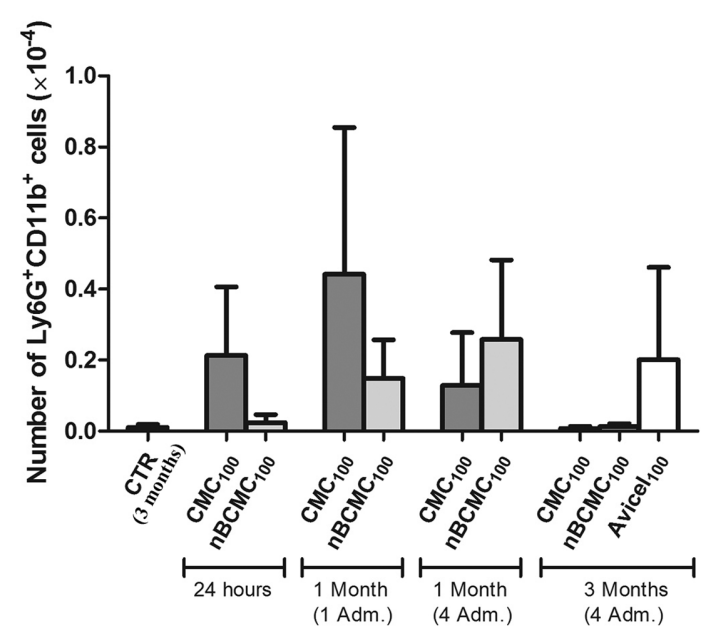

(D)

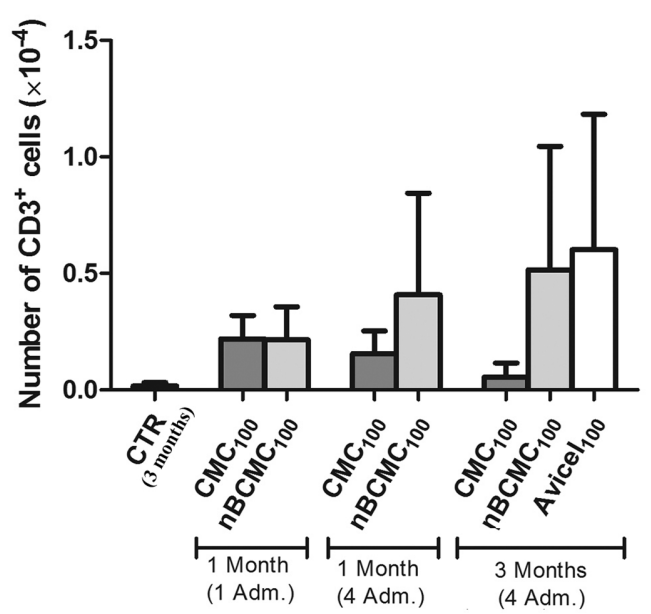

Fig. 9. Cell profiles in BAL fluid of C57BL/6 mice $24 \mathrm{hr}, 1$ month and 3 months post-exposure to one or four doses of $C M C_{100}, n B_{C M C}$ and Avicel ${ }_{100}$. The number of (A) macrophages, (B) neutrophils, (C) B cells and (D) T cells was assessed by flow cytometry. Means \pm $\mathrm{SD}$ ( $\mathrm{n}=3$ or 5 mice per group). ${ }^{* *} p<0.001$ comparing $\mathrm{nBCMC}_{100}$ (1 month, $1 \mathrm{adm}$.) with $\mathrm{CMC}_{100}$ (1 month, $1 \mathrm{adm}$.).

the BAL of mice treated with single or repeated doses of $\mathrm{CMC}_{100}$ and $\mathrm{nBCMC}_{100}$ as compared to control samples (no treatment). However, this increase in cell numbers did not reach statistical significance, mostly due to the high variability in the number of inflammatory cell numbers of those populations recovered in the BAL fluids among individuals within each group. The $\mathrm{F} 4 / 80^{+} \mathrm{CD} 11 \mathrm{c}^{+} \mathrm{CD} 11 \mathrm{~b}^{\text {int }}$ cell population was the predominant one at all assessed time points and treatments (Supplementary Fig. 2). Furthermore, MPO activity was quantified in BAL fluid as a further indicator of neutrophil inflammation. As shown in Fig. 10, no significant alterations were observed between control and treatment groups in MPO activity, in agreement with the flow cytometry results. Presence of lymphocytes in BAL fluid in this study was also assessed, 1 and 3 months after treatments, since these cells are responsible for the adaptive immune response that becomes only noticeable after the early phase of the inflammatory process (57). Fig. 9C and D shows that $\mathrm{B}$ cell $\left(\mathrm{CD} 19^{+}\right)$and $\mathrm{T}$ cell $\left(\mathrm{CD}^{+}\right)$numbers detected in BAL fluids recovered from the mice treated with $\mathrm{CMC}_{100}$ or $\mathrm{nBCMC}_{100}$, only slightly vary from those of controls. Nevertheless, and although not reaching statistical differences, mean values of $\mathrm{T}$ cell numbers for all assessed groups were well above the one of the control. The BAL fluids of Avicel ${ }_{100}$ treated mice, recovered 3 months after the first of four weekly treatments, presented the highest numbers of inflammatory cells (Fig. 9A-9D), that were predominantly of mononuclear character. At this time point $\mathrm{nBCMC}_{100}$ and Avicel $_{100}$ similarly induced the recruitment of $\mathrm{T}$ cells. However, the latter treatment was the one inducing the highest accumulation of B cells in the BAL fluid, which 


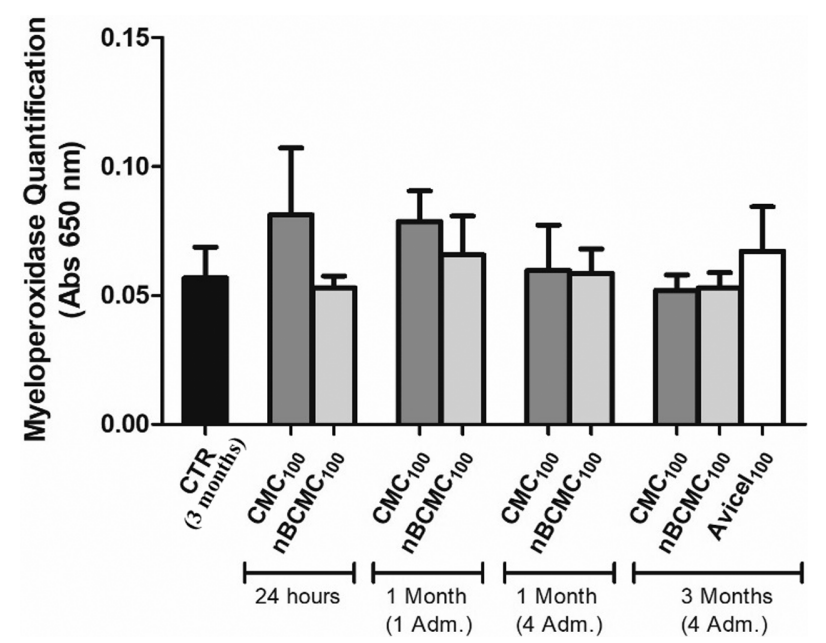

Fig. 10. Pulmonary inflammation of $\mathrm{C} 57 \mathrm{BL} / 6$ mice intratracheally instilled with $\mathrm{CMC}_{100}, \mathrm{nBCMC}_{100}$ and Avicel $_{100}$ over time (up to 3 months) evaluated by the myeloperoxidase (MPO) quantification in BAL fluid. Means $\pm S D(n=3$ or 5 mice per group). No statistically significant differences were detected.

was consistent with the presence of lymphocytes and plasma cells detected by histology analysis in the lung tissue. Altogether, these results further indicate that inflammatory effects of nanofibers inhalation are non-negligible.

\section{DISCUSSION}

Many applications for cellulose nanofibers have been proposed and the trend is for the number of patents to continue rising (19). BC presents a very attractive alternative to plant cellulose in some of these applications, given its purity. Independently of the production method used, BC nanofibrils become airborne, and potentially inhalable, upon drying. The production on an industrial scale of different nanoparticulate celluloses further emphasizes the need to carefully evaluate the potential biological impact of these materials.

Different molecules or polymers have been used to enhance colloidal suspension/dispersion of the cellulose fibers. CMC, a water soluble and linear anionic polysaccharide derived from cellulose, is frequently used to reduce fibers flocculation since it can reduce fiber-fiber interactions (58). It was demonstrated that a concentration ratio of $\mathrm{CMC} / \mathrm{BC}$ nanocrystals above 0.05 increases the colloidal stability/dispersion of BC nanocrystals obtained through acid hydrolysis, which normally tends to aggregate due to hydrogen bonds and van der Waals attraction (59). The addition of $\mathrm{CMC}$ to the $\mathrm{BC}$ nanofibers significantly increased the surface charge and improved the colloidal stability $(60,61)$. Indeed, after thermal sterilization, the nanofibrils suspension remained stable and homogeneous. However, since the presence of CMC was found to have some biological impact in the in vivo trials, a suspension of $\mathrm{nBC}$ was sterilized by gamma irradiation, yielding a stable dispersion of the fibers at room temperature that could be administrated in the mice. Thus, both $\mathrm{nBCMC}$ and $\mathrm{nBC}$ were studied in vivo.

Crystallinity is a major factor that specifically influences the mechanical properties of materials. The crystallinity degree of $\mathrm{BC}$ membranes formed in static culture was previously reported as ranging between $60-90 \%$ (13). The high number of inter- and intra-hydrogen bonds between adjacent chains of glucans creates a regular crystalline arrangement, resulting in the distinct diffraction pattern, swelling, and reactivity of cellulose (62). We speculate that the slight reduction of the crystallinity of the $\mathrm{BC}$ nanofibers in the presence of CMC may arise from the stabilization of the fibers, which upon drying reduce the interfibers interaction, so impairing a slight crystallinity increase related to the aggregation of the fibers and its tight interaction.

The width of the nanofibrils in the $\mathrm{nBC}$ and $\mathrm{nBCMC}$ samples is not significantly different and is in agreement with data from the literature $(13,63,64)$. In addition, no significant formation of nanofibrils bundles were observed in the presence of CMC, confirming the efficacy of the dispersing agent. These results showed that $\mathrm{CMC}$ dispersed well the $\mathrm{nBC}$ and maintained the suspension stable after autoclaving. Furthermore, the presence of CMC during the homogenization did not cause an additional defibrillation of the bacterial cellulose nanofibrils. It is worth noting that a simple deconstruction process using a laboratory blender was able to separate nanofibrils from the complex $3 \mathrm{D}$ network of BC cubes into a suspension of individual nanofibrils. However, the high standard deviations associated to the average width of the $\mathrm{BC}$ nanofibrils indicate that the homogenization process introduces a relatively high heterogeneity to nanofibrils production. Nevertheless, other complex processes of nanofibrils production described in the literature, requiring higher energy and time, have also failed to achieve homogeneity (64-66).

The presence of endotoxins in the outer membranes of most Gram-negative bacteria (44), is one of the main concerns when using materials of microbial origin for biomedical applications. The accepted maximum limit for endotoxin set by the Food and Drug Administration (FDA) for medical devices is 0.5 endotoxin units $(\mathrm{EU}) / \mathrm{mL}(67)$. The endotoxin levels in the $\mathrm{BC}$ nanofibers produced in this work are very close to, or even below, the FDA approved limit values (67). Furthermore, it was described that the endotoxin limits for drugs used in vivo studies using mice as preclinical research model are 1.5 and $3 \mathrm{EU} / \mathrm{mL}$, depending on the used dose $(0.100$ or $0.050 \mathrm{~mL} / \mathrm{h}$, respectively) (68).

Considering that, it is not expected that our material should induce adverse reaction in vivo since the detected 
endotoxin levels are below the ones reported in the literature for in vivo assays (68). Several studies addressed this issue (69,70). Martinez Avila et al. (69) obtained BC samples with endotoxin levels of $0.1 \mathrm{EU} / \mathrm{mL}$. Nevertheless, the purification/depyrogenation method used in that work is very complex and time consuming. The perfusion of the BC cylinders with $\mathrm{NaOH}$ for 28 days was followed by the perfusion with deionized water for 7 days and the washing of the densified bacterial nanocellulose hydrogel disks in sterile and non-pyrogenic conditions for 14 days. Furthermore, the authors performed the endotoxin quantification after endotoxicity extraction with endotoxin-free water (69). Comparatively, the approach used in this study, adapted from Leitão et al. (71), is much faster and simpler, yielding samples with low endotoxin levels.

The assessment of the in vitro and in vivo effect of cellulose nanofibrils is an essential element of a toxicological study. Overall, the in vitro results show that the cellulose samples did not significantly alter metabolic activity levels, up to $10 \mu \mathrm{g}(0.2 \mathrm{mg} / \mathrm{mL}$ ), after $24 \mathrm{hr}$ exposure (Fig. $3)$. These results are in accordance to what is described in the literature $(47,48)$. In fact, Vartiainen et al. (47) showed that microfibrillated cellulose does not cause a significant decrease in the viability of the mouse macrophage cell line RAW 264.7 after $24 \mathrm{hr}$ exposure to three different fibers concentrations $(30,100$ and $300 \mu \mathrm{g} / \mathrm{mL})$. Moreover, Lopes et al. (48) showed that unmodified and modified nanofibrillated cellulose did not induce cytotoxicity in human dermal fibroblasts (HDR), lung fibroblast (MRC-5) and phorbol myristate acetate (PMA)-differentiated macrophage (THP-1) cell lines after exposure for $24 \mathrm{hr}$ to different doses $(50,100,250$ and $500 \mu \mathrm{g} / \mathrm{mL})$. Regarding BC, Moreira et al. (72) showed that the nanofibrils affected fibroblast proliferation, by $15-20 \%$, only after $72 \mathrm{hr}$.

Considering the in vivo results, the analysis of the BAL fluid provided no evidence of acute lung toxicity or injury and of air-blood barrier dysfunction. However, histological analysis revealed a mild multifocal to coalescing acute bronchioalveolar inflammation. It is intriguing that all concentrations tested yielded a similar outcome, as no dosage-dependent effects were noticed. On the other hand, both CMC and nBCMC samples gave similar outcomes in the histological analysis. In order to rule out an effect exclusively associated to the CMC, we decided to include in the following studies a group consisting of $\mathrm{nBC}$ without CMC. In order to do so, the fibers were sterilized by gamma irradiation, which did not compromise the colloidal stability of the fibers (unlike thermal sterilization). We opted to proceed using the higher concentrations, in order to mimetize situations of heavier/chronic exposition, leading to the accumulation of higher amounts in the lungs, such as may occur in workers of nanocellulose producing plants.

In this study, a dose of $16 \mathrm{mg} / \mathrm{kg}$ of fibers was used, which is equivalent to a cumulative dose of $400 \mu \mathrm{g} / \mathrm{mouse}$ after four treatments $\left(6.7 \mathrm{mg} / \mathrm{m}^{2}\right.$, taking into consideration the total alveolar surface area of mouse lung $\left(0.06 \mathrm{~m}^{2}\right)$ (1)). Specifically, human equivalent exposure to a deposited cumulative dose of $400 \mu \mathrm{g}\left(6.7 \mathrm{mg} / \mathrm{m}^{2}\right)$ of cellulose can be achieved after $\sim 71$ days at allowable exposure limits of $5 \mathrm{mg} / \mathrm{m}^{3}$ of cellulose, as defined by Occupational Safety \& Health Administration (OSHA) (29 CFR (73) 1910.1000, Table Z-1). These calculations were performed as proposed by Yanamala et al. (74), considering an alveolar lung surface areas of $102 \mathrm{~m}^{2}$ for human (75), a lung ventilation of $9.6 \mathrm{~m}^{3} / 8 \mathrm{hr}$ (76) and a pulmonary alveolar deposition fraction of $20 \%$ (77). Thus, the cumulative dose used in this work represents a relevant case-study considering the human exposure limits to cellulose particles.

The histological analysis revealed the medial hypertrophy of pulmonary arteries in the presence of CMC, nBCMC and $\mathrm{nBC}$, which is of particular concern. This lesion is irreversible and associated with chronic pulmonary hypertension (78). However, the animals showed no cardiac or hepatic hypertension-related lesions.

Even if the treatment with $\mathrm{BC}$ nanofibrils did not cause damage to the air-blood barrier nor promoted oxidative stress, the histopathological analysis seems to be consistent with some reports of in vitro and in vivo toxicity of plant cellulose nanofibrils, which showed alterations in the normal physiology of the lung tissues $(1,34,55,56)$. Adamis et al. (56) proved that intratracheal administration of cellulose to rats induced fibrosis alveobronchiolitis, an increase of LDH and acid phosphatase, as a result of cell damage, and an increase in protein levels that was attributed to the increased capillary permeability in the alveoli. Tátrai et al. (79) showed that a single administration in rats cellulose promoted fibrosing granulomatous alveobronchiolitis and lead to the degradation of the alveolo-capillary morphological functional unit. In fact, different studies confirmed the formation of pulmonary fibrosis after cellulose nanoparticles inhalation $(1,31,32,80)$. A more recent study also showed that wood pulp-derived cellulose nanocrystals elicit in mice lungs a dose-dependent oxidative stress, by increasing the formation of two oxidative protein modifications, 4-hydroxynonenal (4-HNE), a common byproduct of lipid peroxidation, and protein carbonyl, a product of protein oxidation, and acute pulmonary damage by the increasing the LDH release (34). Additionally, Shvedova et al. (1) confirmed that exposure to respirable cellulose nanocrystals impaired pulmonary functions, an effect that was more pronounced in female mice. The treatment caused pulmonary damage, evaluated by a significant increase in the levels of $\mathrm{LDH}$ and total protein content, and induced oxidative stress leading to the increase levels of protein carbonyl. Likewise Yanamala et al. (34), Clift et al. (55) observed that paper-derived cellulose nanocrystals promote a dose-dependent cell damage by the release of $\mathrm{LDH}$ 
in the human bronchial epithelial cell-line 16HBE14o- in the triple cell co-culture model. This hazardous effect described in the literature could be mainly mediated by the elongated shape of the nanofibrils, which makes clearance difficult and causes tissue damage due to frustrated phagocytosis (32). Moreover a report has shown that in mice intraperitoneally injected $\mathrm{BC}$ nanofibrils are nontoxic to endothelial cells (81). In this study, BC nanofibrils did not induce alterations in the tested biochemical parameters, in the normal behavior of the mice or in the physiological/macroscopic post-mortem parameters (81). However, while generally considered safe and biocompatible, BC nanofibers can lead to complications and health risks, if breathable, by affecting the lungs, as suggested by the here shown results. Due to its fibrous nature (microns in length despite de nanometric cross-section), cellulose clearance half-time can be up to hundreds of days to years $(82,83)$, which potentiates the negative impact for the lungs. Cellulose nanofibers intra- and inter-chain hydrogen bonding network make this polymer relatively stable and strong, not easily degradable (82). In fact, it was reported by Stefaniak et al. (83) that the macrophages phagolysosome's acidic $\mathrm{pH}$ is far from sufficient for cellulose degradation. Moreover, as it is known mammals lack the enzymatic machinery to degrade cellulose (84).

Alveolar macrophages play in the air-exposed lung an important role in the recognition, processing and clearance of particulates (34). Furthermore, during the immune reaction to inhaled particulates and associated with impairment of pulmonary clearance, neutrophils are recruited and activated $(32,85)$. When the phagocytes are unable to degrade foreign particles, this can lead to cell damage due to a reduction in motility (53) and formation of giant cells, leading to foreign body reaction and a chronic inflammatory process. Consequently, these events stimulate an adaptive immune response that is mediated by lymphocyte cells (85).

Despite the analysis of BAL did not show a significant increase in lung immune cells, histopathology analysis seems consistent with the literature concerning the lung effect of inhalable vegetable cellulose nanofibrils $(1,32-$ 34) since it confirms that $\mathrm{BC}$ nanofibrils induce an acute/ chronic bronchoalveolar inflammation in mouse lungs.

Particulate matter in the lungs is mostly cleared via phagocytosis in the alveoli. When the clearance capacity of phagocytes is unable to degrade foreign particles this can lead to cell damage (53) and cause acute/chronic inflammation in the lungs by the recruitment of phagocytic cells, like monocyte/macrophages and neutrophils, and lymphocytes into the alveolar region (32).

Endes et al. (86) showed, using a 3D co-culture system of the human epithelial airway barrier, that longer nanocrystalline cellulose exhibit a lower cell clearance than the shorter one, an effect the authors attributed to stronger fiber-fiber interaction. Furthermore, no significant cytotoxicity was observed by the use of this aerosolized cellulosic material. Cullen et al. $(31,32)$ showed that inhalation of processed wood cellulose nanofibrils of various sizes caused a marked but transient inflammatory response characterized by neutrophils recruitment, which did not progress after a recovery period of 28 days. In fact, at the bifurcations of the terminal and respiratory bronchioles, aggregation of macrophages and adjacent epithelial cells was observed, as well as small solid lesions formed by interstitialization of macrophages and fibroblasts that had the appearance of microgranulomas (31,32). A more recent study demonstrated that bolus administration of respirable plant cellulose nanocrystals caused an acute inflammatory response by accelerating the recruitment of neutrophil, lymphocytes and eosinophils to the mice lung after $24 \mathrm{hr}$ post-exposure (34). Furthermore, it was demonstrated that these effects were markedly more pronounced in females compared to male mice (1), since exposure to plant cellulose nanocrystals promoted up-regulation of IL-17A, responsible to induce the neutrophil production and recruitment. Furthermore, histological sections of the lungs after 3 months' exposure revealed chronic peribronchial and perivascular inflammation and numerous alveolar macrophages, including multi-nucleated giant cells, which is a sign of chronic inflammation. The presence of these cells was more pronounced in female mice, which overexpress both IL-4 and IL-13 (1). Catalán et al. (33) showed that nanofibrillated cellulose administered at low doses induced a significant increase in the macrophages and lymphocytes number in mice lungs whereas high doses significantly increased neutrophils and eosinophils. The histological examination of the lungs at higher doses showed neutrophils around the small and large bronchi as well as neutrophilic accumulation in the alveoli (33). Although BAL samples collected at 3 months exposure to both $\mathrm{nBCMC}_{100}$ and Avicel ${ }_{100}$ contained elevated numbers of T cells, Avicel $_{100}$ was more potent in inducing B-cell accumulation. The microcristaline vs nanofibrous nature of the materials may justify the disparate effects on the chronic inflammatory profile.

The results obtained in this study suggest that the presence of $\mathrm{BC}$ nanofibrils in the lungs may pose serious health risks. As referred, the inherent inability to digest the $\mathrm{BC}$ nanofibrils, due to the lack of the enzymatic machinery, can explain the persistence of cellulose in the lungs and therefore the observed damage and inflammation. Nevertheless, the accessibility and lung deposition of inhalable particles strongly depends on its size. For instance, microparticles $(1 \mu \mathrm{m}<$ particle $<5 \mu \mathrm{m})$ are considerably more effective in penetrating deeper into the lungs than larger particles (87). Considering that $\mathrm{BC}$ nanofibrils possess some micrometers of length (in particular, powdered $\mathrm{BC}$ formulations are likely to present a few tenth or hun- 
dred micrometers), their inhalation through aerosol and consequent deposition in deep areas of the lungs will be expectedly difficult, decreasing its potential negative impact.

\section{ACKNOWLEDGMENTS}

The authors acknowledge Embrapa Tropical Agroindustry and Coordination for the Improvement of Higher Education Personnel (CAPES) and the project under the bilateral program FCT/CAPES: Bacterial Cellulose: a platform for the development of bionanoproducts for funding this research.

This work was also financially supported by: European Investment Funds by FEDER/COMPETE/POCI - Operational Competitiveness and Internationalization Program, under Project POCI-01-0145-FEDER-006958, National Funds by FCT - Portuguese Foundation for Science and Technology, Project POCI-01-0145-FEDER-006939 (Laboratoy for Process Engineering, Environment, Biotechnology and Energy - LEPABE funded by FEDER, funds through COMPETE2020 - Programa Operacional Competitividade e Internacionalização (POCI) - and by national funds through FCT. Rui Gil da Costa is supported by grant $n^{\circ}$ SFRH/BPD/85462/2012 from FCT, financed by the Portuguese Government and the Social European Fund. This study was supported by the Portuguese Foundation for Science and Technology (FCT) also under the scope of the strategic funding of UID/BIO/04469/2013 unit and COMPETE 2020 (POCI-01-0145-FEDER-006684) and BioTecNorte operation (NORTE-01-0145-FEDER-000004) funded by the European Regional Development Fund under the scope of Norte2020 - Programa Operacional Regional do Norte.

\section{CONFLICT OF INTEREST}

The authors declare that they have no conflicts of interests.

Received June 19, 2018; Revised September 19, 2018; Accepted October 4, 2018

\section{REFERENCES}

1. Shvedova, A.A., Kisin, E.R., Yanamala, N., Farcas, M.T., Menas, A.L., Williams, A., Fournier, P.M., Reynolds, J.S., Gutkin, D.W., Star, A., Reiner, R.S., Halappanavar, S. and Kagan, V.E. (2016) Gender differences in murine pulmonary responses elicited by cellulose nanocrystals. Part. Fibre Toxicol., 13, 28.

2. Vasconcelos, N.F., Feitosa, J.P., da Gama, F.M., Morais, J.P., Andrade, F.K., de Souza Filho, M.S. and Rosa, M.F. (2017) Bacterial cellulose nanocrystals produced under different hydrolysis conditions: Properties and morphological features. Carbohydr. Polym., 155, 425-431.

3. Martínez-Sanz, M., Olsson, R.T., Lopez-Rubio, A. and
Lagaron, J.M. (2012) Development of bacterial cellulose nanowhiskers reinforced EVOH composites by electrospinning. J. Appl. Polym. Sci., 124, 1398-1408.

4. Svensson, A., Nicklasson, E., Harrah, T., Panilaitis, B., Kaplan, D.L., Brittberg, M. and Gatenholm, P. (2005) Bacterial cellulose as a potential scaffold for tissue engineering of cartilage. Biomaterials, 26, 419-431.

5. Leitão, A., Silva, J., Dourado, F. and Gama, M. (2013) Production and characterization of a new bacterial cellulose/ poly(vinyl alcohol) nanocomposite. Materials, 6, 1956-1966.

6. Ummartyotin, S. and Manuspiya, H. (2015) A critical review on cellulose: from fundamental to an approach on sensor technology. Renew. Sust. Energ. Rev., 41, 402-412.

7. Solway, D.R., Consalter, M. and Levinson, D.J. (2010) Microbial cellulose wound dressing in the treatment of skin tears in the frail elderly. Wounds, 22, 17-19.

8. Fontana, J.D., de Souza, A.M., Fontana, C.K., Torriani, I.L., Moreschi, J.C., Gallotti, B.J., de Souza, S.J., Narcisco, G.P., Bichara, J.A. and Farah, L.F. (1990) Acetobacter cellulose pellicle as a temporary skin substitute. Appl. Biochem. Biotechnol., 24-25, 253-264.

9. Andrade, F.K., Costa, R., Domingues, L., Soares, R. and Gama, M. (2010) Improving bacterial cellulose for blood vessel replacement: Functionalization with a chimeric protein containing a cellulose-binding module and an adhesion peptide. Acta Biomater., 6, 4034-4041.

10. Bäckdahl, H., Risberg, B. and Gatenholm, P. (2011) Observations on bacterial cellulose tube formation for application as vascular graft. Mater. Sci. Eng. C., 31, 14-21.

11. Leitao, A.F., Gupta, S., Silva, J.P., Reviakine, I. and Gama, M. (2013) Hemocompatibility study of a bacterial cellulose/ polyvinyl alcohol nanocomposite. Colloids Surf. B Biointerfaces, 111, 493-502.

12. Backdahl, H., Helenius, G., Bodin, A., Nannmark, U., Johansson, B.R., Risberg, B. and Gatenholm, P. (2006) Mechanical properties of bacterial cellulose and interactions with smooth muscle cells. Biomaterials, 27, 2141-2149.

13. Andrade, F.K., Pertile, R.A.N., Dourado, F. and Gama, M. (2010) Bacterial cellulose: properties, production and applications in Cellulose: Structure and Properties, Derivatives and Industrial Uses (Lejeune, A. and Deprez, T. Eds). Nova Science Publishers, Inc., pp. 427-458.

14. Klemm, D., Schumann, D., Udhardt, U. and Marsch, S. (2001) Bacterial synthesized cellulose - artificial blood vessels for microsurgery. Prog. Polym. Sci., 26, 1561-1603.

15. Fu, L.N., Wang, W., Yu, L.J., Zhang, S.M. and Yang, G. (2009) Fabrication of novel cellulose/chitosan artificial skin composite. Mater. Sci. Forum, 610-613, 1034-1038.

16. Millon, L.E., Guhados, G. and Wan, W. (2008) Anisotropic polyvinyl alcohol-Bacterial cellulose nanocomposite for biomedical applications. J. Biomed. Mater. Res. Part B Appl. Biomater, 86, 444-452.

17. Martinez-Sanz, M., Lopez-Rubio, A. and Lagaron, J.M. (2012) Optimization of the dispersion of unmodified bacterial cellulose nanowhiskers into polylactide via melt compounding to significantly enhance barrier and mechanical properties. Biomacromolecules, 13, 3887-3899.

18. Zhou, C. and Wu, Q. (2012) Recent development in applications of cellulose nanocrystals for advanced polymer-based 
nanocomposites by novel fabrication strategies in Nanocrystals: Synthesis, Characterization and Applications (Neralla, S. Ed). IntechOpen.

19. Charreau, H., Foresti, M.L. and Vazquez, A. (2013) Nanocellulose patents trends: a comprehensive review on patents on cellulose nanocrystals, microfibrillated and bacterial cellulose. Recent Pat. Nanotechnol., 7, 56-80.

20. Li, Y. and Ragauskas, A.J. (2011) Cellulose nano whiskers as a reinforcing filler in polyurethanes in Avances in Diverse Industrial Applications Of Nanocomposites (Reddy, B. Ed.). IntechOpen, pp. 19-36.

21. Pitkänen, M., Kangas, H., Laitinen, O., Sneck, A., Lahtinen, P., Peresin, M.S. and Niinimäki, J. (2014) Characteristics and safety of nano-sized cellulose fibrils. Cellulose, 21, 3871-3886.

22. Dugan, J.M., Gough, J.E. and Eichhorn, S.J. (2013) Bacterial cellulose scaffolds and cellulose nanowhiskers for tissue engineering. Nanomedicine (Lond.), 8, 287-298.

23. Martínez-Sanz, M., Lopez-Rubio, A. and Lagaron, J.M. (2011) Optimization of the nanofabrication by acid hydrolysis of bacterial cellulose nanowhiskers. Carbohydr. Polym., $\mathbf{8 5}, 228-236$.

24. Nechyporchuk, O., Belgacem, M.N. and Bras, J. (2016) Production of cellulose nanofibrils: a review of recent advances. Ind. Crops Prod., 93, 2-25.

25. Cullen, R., Miller, B., Jones, A. and Davis, J. (2002) Toxicity of cellulose fibres. Ann. Occup. Hyg., 46, 81-84.

26. Future Markets Inc. (2012) Nanocellulose: A Technology and Market Study, pp. 35.

27. Hull, M. and Bowman, D. (2014) Nanotechnology Environmental Health and Safety (2nd edition), Elsevier.

28. Kovacs, T., Naish, V., O'Connor, B., Blaise, C., Gagne, F., Hall, L., Trudeau, V. and Martel, P. (2010) An ecotoxicological characterization of nanocrystalline cellulose (NCC). Nanotoxicology, 4, 255-270.

29. Shi, Q., Li, Y., Sun, J., Zhang, H., Chen, L., Chen, B., Yang, H. and Wang, Z. (2012) The osteogenesis of bacterial cellulose scaffold loaded with bone morphogenetic protein-2. Biomaterials, 33, 6644-6649.

30. Zaborowska, M., Bodin, A., Bäckdahl, H., Popp, J., Goldstein, A. and Gatenholm, P. (2010) Microporous bacterial cellulose as a potential scaffold for bone regeneration. Acta Biomater, 6, 2540-2547.

31. Cullen, R.T., Miller, B.G., Jones, A.D. and Davis, J.M.G. (2002) Toxicity of cellulose fibres. Ann. Occup. Hyg., 46, 81-84.

32. Cullen, R.T., Searl, A., Miller, B.G., Davis, J.M. and Jones, A.D. (2000) Pulmonary and intraperitoneal inflammation induced by cellulose fibres. J. Appl. Toxicol., 20, 49-60.

33. Catalan, J., Rydman, E., Aimonen, K., Hannukainen, K.S., Suhonen, S., Vanhala, E., Moreno, C., Meyer, V., Perez, D.D., Sneck, A., Forsstrom, U., Hojgaard, C., Willemoes, M., Winther, J.R., Vogel, U., Wolff, H., Alenius, H., Savolainen, K.M. and Norppa, H. (2016) Genotoxic and inflammatory effects of nanofibrillated cellulose in murine lungs. Mutagenesis, 32, 23-32.

34. Yanamala, N., Farcas, M.T., Hatfield, M.K., Kisin, E.R., Kagan, V.E., Geraci, C.L. and Shvedova, A.A. (2014) In vivo evaluation of the pulmonary toxicity of cellulose nano- crystals: a renewable and sustainable nanomaterial of the future. ACS Sustain. Chem. Eng., 2, 1691-1698.

35. Schramm, M. and Hestrin, S. (1954) Synthesis of cellulose by Acetobacter xylinum. I. Micromethod for the determination of celluloses. Biochem. J., 56, 163-166.

36. Delgado, A.V., Gonzalez-Caballero, F., Hunter, R.J., Koopal, L.K. and Lyklema, J. (2007) Measurement and interpretation of electrokinetic phenomena. J. Colloid. Interface Sci., 309, 194-224.

37. Segal, L., Creely, J.J., Martin, A.E. and Conrad, C.M. (1959) An empirical method for estimating the degree of crystallinity of native cellulose using the X-ray diffractometer. Text. Res. J., 29, 786-794.

38. Torrado, E., Fraga, A.G., Logarinho, E., Martins, T.G., Carmona, J.A., Gama, J.B., Carvalho, M.A., Proenca, F., Castro, A.G. and Pedrosa, J. (2010) IFN-gamma-dependent activation of macrophages during experimental infections by Mycobacterium ulcerans is impaired by the toxin mycolactone. J. Immunol., 184, 947-955.

39. Mullane, K.M., Kraemer, R. and Smith, B. (1985) Myeloperoxidase activity as a quantitative assessment of neutrophil infiltration into ischemic myocardium. J. Pharmacol. Methods, 14, 157-167.

40. Renne, R., Brix, A., Harkema, J., Herbert, R., Kittel, B., Lewis, D., March, T., Nagano, K., Pino, M., Rittinghausen, S., Rosenbruch, M., Tellier, P. and Wohrmann, T. (2009) Proliferative and nonproliferative lesions of the rat and mouse respiratory tract. Toxicol. Pathol., 37, 5S-73S.

41. Lee, K.-Y., Quero, F., Blaker, J.J., Hill, C.A.S., Eichhorn, S.J. and Bismarck, A. (2011) Surface only modification of bacterial cellulose nanofibres with organic acids. Cellulose, 18, 595-605.

42. Mirhosseini, H., Tan, C.P., Hamid, N.S.A. and Yusof, S. (2008) Effect of Arabic gum, xanthan gum and orange oil contents on $\zeta$-potential, conductivity, stability, size index and $\mathrm{pH}$ of orange beverage emulsion. Colloids Surf. A, 315, 4756.

43. Duarte, E.B., das Chagas, B.S., Andrade, F.K., Brígida, A.I.S., Borges, M.F., Muniz, C.R., Souza Filho, M.d.S.M., Morais, J.P.S., Feitosa, J.P.A. and Rosa, M.F. (2015) Production of hydroxyapatite-bacterial cellulose nanocomposites from agroindustrial wastes. Cellulose, 22, 3177-3187.

44. Raetz, C.R. and Whitfield, C. (2002) Lipopolysaccharide endotoxins. Annu. Rev. Biochem., 71, 635-700.

45. Cundell, A.M. (2014) Bacterial endotoxin requirements for dry powder inhalants and their excipients: are they critical quality attributes? PDA J. Pharm. Sci. Technol., 68, 386393.

46. U.S. Food and Drug Administration (1987) Guideline on Validation of the Limulus Amebocyte Lysate Test as an Endproduct Endotoxin Test for Human and Animal Parenteral Drugs, Biological Products and Medical Devices, US Department of Health and Human Services, Public Health Service, Food and Drug Administration.

47. Vartiainen, J., Pöhler, T., Sirola, K., Pylkkänen, L., Alenius, H., Hokkinen, J., Tapper, U., Lahtinen, P., Kapanen, A., Putkisto, K., Hiekkataipale, P., Eronen, P., Ruokolainen, J. and Laukkanen, A. (2011) Health and environmental safety aspects of friction grinding and spray drying of microfibrillated cel- 
lulose. Cellulose, 18, 775-786.

48. Lopes, V.R., Sanchez-Martinez, C., Strømme, M. and Ferraz, N. (2017) In vitro biological responses to nanofibrillated cellulose by human dermal, lung and immune cells: surface chemistry aspect. Part. Fibre Toxicol., 14, 1.

49. Kim, G.-D., Yang, H., Park, H.R., Park, C.-S., Park, Y.S. and Lee, S.E. (2013) Evaluation of immunoreactivity of in vitro and in vivo models against bacterial synthesized cellulose to be used as a prosthetic biomaterial. BioChip J., 7, 201-209.

50. Meng, G., Zhao, J., Wang, H.M., Ding, R.G., Zhang, X.C., Huang, C.Q. and Ruan, J.X. (2010) Cell injuries of the blood-air barrier in acute lung injury caused by perfluoroisobutylene exposure. J. Occup. Health, 52, 48-57.

51. Noël-Georis, I., Bernard, A., Falmagne, P. and Wattiez, R. (2001) Proteomics as the tool to search for lung disease markers in bronchoalveolar lavage. Dis. Markers, 17, 271284.

52. Henderson, R.F., Damon, E.G. and Henderson, T.R. (1978) Early damage indicators in the the lung I. Lactate dehydrogenase activity in the airways. Toxicol. Appl. Pharmacol., 44, 291-297.

53. Mantecca, P., Sancini, G., Moschini, E., Farina, F., Gualtieri, M., Rohr, A., Miserocchi, G., Palestini, P. and Camatini, M. (2009) Lung toxicity induced by intratracheal instillation of size-fractionated tire particles. Toxicol. Lett., 189, 206-214.

54. Swedin, L., Arrighi, R. and ersson-Willman, B., Murray, A., Chen, Y., Karlsson, M.C.I., Georén, S.K., Tkach, A.V., Shvedova, A.A., Fadeel, B., Barragan, A. and Scheynius, A. (2012) Pulmonary exposure to single-walled carbon nanotubes does not affect the early immune response against Toxoplasma gondii. Part. Fibre Toxicol., 9, 16.

55. Clift, M.J., Foster, E.J., Vanhecke, D., Studer, D., Wick, P., Gehr, P., Rothen-Rutishauser, B. and Weder, C. (2011) Investigating the interaction of cellulose nanofibers derived from cotton with a sophisticated 3D human lung cell coculture. Biomacromolecules, 12, 3666-3673.

56. Adamis, Z., Tatrai, E., Honma, K. and Ungvary, G. (1997) In vitro and in vivo assessment of the pulmonary toxicity of cellulose. J. Appl. Toxicol., 17, 137-141.

57. Chaplin, D.D. (2010) Overview of the immune response. $J$. Allergy Clin. Immunol., 125, S3-23.

58. Liimatainen, H., Haavisto, S., Haapala, A. and Niinimäki, J. (2009) Influence of adsorbed and dissolved carboxymethyl cellulose on fibre suspension dispersing, dewaterability, and fines retention. Bioresources, 4, 321-340.

59. Winter, H.T., Cerclier, C., Delorme, N., Bizot, H., Quemener, B. and Cathala, B. (2010) Improved colloidal stability of bacterial cellulose nanocrystal suspensions for the elaboration of spin-coated cellulose-based model surfaces. Biomacromolecules, 11, 3144-3151.

60. Khaled, B. and Abdelbaki, B. (2012) Rheological and electrokinetic properties of carboxymethylcellulose-water dispersions in the presence of salts. Int. J. Phys. Sci., 7, 1790 1798.

61. He, M., Cho, B.-U., Lee, Y.K. and Won, J.M. (2016) Utilizing cellulose nanofibril as an eco-friendly flocculant for filler flocculation in papermaking. BioRes, 11, 10296-10313.

62. Sheykhnazari, S., Tabarsa, T., Ashori, A., Shakeri, A. and Golalipour, M. (2011) Bacterial synthesized cellulose nano- fibers; Effects of growth times and culture mediums on the structural characteristics. Carbohydr. Polym., 86, 1187-1191.

63. Gama, M., Gatenholm, P. and Klemm, D. (2012) Bacterial NanoCellulose: a Sophisticated Multifunctional Material., CRC Press, Boca Raton, FL.

64. Kose, R., Mitani, I., Kasai, W. and Kondo, T. (2011) "Nanocellulose" as a single nanofiber prepared from pellicle secreted by Gluconacetobacter xylinus using aqueous counter collision. Biomacromolecules, 12, 716-720.

65. Saito, T., Nishiyama, Y., Putaux, J.L., Vignon, M. and Isogai, A. (2006) Homogeneous suspensions of individualized microfibrils from TEMPO-catalyzed oxidation of native cellulose. Biomacromolecules, 7, 1687-1691.

66. Lavoine, N., Desloges, I., Dufresne, A. and Bras, J. (2012) Microfibrillated cellulose - its barrier properties and applications in cellulosic materials: a review. Carbohydr. Polym., 90, 735-764.

67. U.S. Food and Drug Administration (2012) Guidance for Industry: Pyrogen and Endotoxins Testing: Questions and Answers, Silver Spring, MD, p. 11.

68. Malyala, P. and Singh, M. (2008) Endotoxin limits in formulations for preclinical research. J. Pharm. Sci., 97, 20412044.

69. Martinez Avila, H., Schwarz, S., Feldmann, E.M., Mantas, A., von Bomhard, A., Gatenholm, P. and Rotter, N. (2014) Biocompatibility evaluation of densified bacterial nanocellulose hydrogel as an implant material for auricular cartilage regeneration. Appl. Microbiol. Biotechnol., 98, 7423-7435.

70. Bodin, A., Bharadwaj, S., Wu, S., Gatenholm, P., Atala, A. and Zhang, Y. (2010) Tissue-engineered conduit using urinederived stem cells seeded bacterial cellulose polymer in urinary reconstruction and diversion. Biomaterials, 31, 88898901.

71. Leitão, A.F., Faria, M.A., Faustino, A.M., Moreira, R., Mela, P., Loureiro, L., Silva, I. and Gama, M. (2016) A novel small-caliber bacterial cellulose vascular prosthesis: production, characterization, and preliminary in vivo testing. Macromol. Biosci., 16, 139-150.

72. Moreira, S., Silva, N.B., Almeida-Lima, J., Rocha, H.A., Medeiros, S.R., Alves, C., Jr. and Gama, F.M. (2009) BC nanofibres: in vitro study of genotoxicity and cell proliferation. Toxicol. Lett., 189, 235-241.

73. Occupational Safety and Health Administration (OSHA) of the United States Department of Labor. CFR Code of Federal Regulations, U.S. Government Printing Office, Office of the Federal Register, Washington, DC.

74. Yanamala, N., Hatfield, M.K., Farcas, M.T., SchweglerBerry, D., Hummer, J.A., Shurin, M.R., Birch, M.E., Gutkin, D.W., Kisin, E., Kagan, V.E., Bugarski, A.D. and Shvedova, A.A. (2013) Biodiesel versus diesel exposure: enhanced pulmonary inflammation, oxidative stress, and differential morphological changes in the mouse lung. Toxicol. Appl. Pharmacol., 272, 373-383.

75. Fröhlich, E., Mercuri, A., Wu, S. and Salar-Behzadi, S. (2016) Measurements of deposition, lung surface area and lung fluid for simulation of inhaled compounds. Front. Pharmacol., 7, 181.

76. Task Group of the International Commission on Radiological Protection. (1994) ICRP Human Respiratory Tract Model 
for Radiological Protection, Ann. ICRP.

77. Bates, D.V., Fish, B.R., Hatch, T.F., Mercer, T.T. and Morrow, P.E. (1966) Deposition and retention models for internal dosimetry of the human respiratory tract. Task group on lung dynamics. Health Phys., 12, 173-207.

78. Beppu, H., Ichinose, F., Kawai, N., Jones, R.C., Yu, P.B., Zapol, W.M., Miyazono, K., Li, E. and Bloch, K.D. (2004) BMPR-II heterozygous mice have mild pulmonary hypertension and an impaired pulmonary vascular remodeling response to prolonged hypoxia. Am. J. Physiol. Lung Cell Mol. Physiol., 287, L1241-L1247.

79. Tátrai, E., Brozik, M., Adamis, Z., Meretey, K. and Ungvary, G. (1996) In vivo pulmonary toxicity of cellulose in rats. J. Appl. Toxicol., 16, 129-135.

80. Muhle, H., Ernst, H. and Bellmann, B. (1997) Investigation of the durability of cellulose fibres in rat lungs. Ann. Occup. Hyg., 41, 184-188.

81. Jeong, S.I., Lee, S.E., Yang, H., Jin, Y.-H., Park, C.-S. and Park, Y.S. (2010) Toxicologic evaluation of bacterial synthesized cellulose in endothelial cells and animals. Mol. Cell. Toxicol., 6, 370-377.

82. Moon, R.J., Martini, A., Nairn, J., Simonsen, J. and Young- blood, J. (2011) Cellulose nanomaterials review: structure, properties and nanocomposites. Chem. Soc. Rev., 40, 39413994.

83. Stefaniak, A.B., Seehra, M.S., Fix, N.R. and Leonard, S.S. (2014) Lung biodurability and free radical production of cellulose nanomaterials. Inhal. Toxicol., 26, 733-749.

84. Zhang, Z., Ortiz, O., Goyal, R. and Kohn, J. (2014) Chapter 23 - biodegradable polymers A2 - Lanza, Robert in Principles of Tissue Engineering (4th edition) (Langer, R. and Vacanti, J. Eds.). Academic Press, Boston, pp. 441-473.

85. Hasenberg, M., Stegemann-Koniszewski, S. and Gunzer, M. (2013) Cellular immune reactions in the lung. Immunol. Rev., 251, 189-214.

86. Endes, C., Mueller, S., Kinnear, C., Vanhecke, D., Foster, E.J., Petri-Fink, A., Weder, C., Clift, M.J. and RothenRutishauser, B. (2015) Fate of cellulose nanocrystal aerosols deposited on the lung cell surface in vitro. Biomacromolecules, 16, 1267-1275.

87. Labiris, N.R. and Dolovich, M.B. (2003) Pulmonary drug delivery. Part I: physiological factors affecting therapeutic effectiveness of aerosolized medications. Br. J. Clin. Pharmacol., 56, 588-599. 